\title{
Effect of Fuel Properties on Spray Development from a Multi-Hole DISI Engine Injector
}

\author{
Z. van Romunde and P.G. Aleiferis \\ University College London, UK
}

\author{
R.F. Cracknell and H.L. Walmsley \\ Shell Global Solutions (UK), Ltd., Thornton, UK
}

Copyright @ 2007 SAE International

\begin{abstract}
Extensive literature exists on spray development, mixing and combustion regarding engine modeling and diagnostics using single-component and model fuels. However, often the variation in data between different fuels, particularly relating to spray development and its effect on combustion, is neglected or overlooked. By injecting into a quiescent chamber, this work quantifies the differences in spray development from a multi-hole direct-injection spark-ignition engine injector for two single-component fuels (iso-octane and $n$-pentane), a non-fluorescing multi-component model fuel which may be used for in-cylinder Laser Induced Fluorescence experiments, and several grades of pump gasoline (with and without additives). High-speed recordings of the sprays were made for a range of fuel temperatures and gas pressures. It is shown that a fuel temperature above that of the lowest boiling point fraction of the tested fuel at the given gas pressure causes a convergence of the spray plumes. Increasing the fuel temperature increases this convergence, whilst an associated increased rate of evaporation tends to reduce the penetration of individual plumes. The convergence increases gradually with increasing fuel temperature until all plumes combine to form a single wider plume with a penetration rate greater than that of the individual plumes. When all plumes are converged to form a single plume along a central axis to all the plumes, any further increase in fuel temperature at the given gas pressure acts to increase the rate of evaporation of the fuel. At experiments up to $180^{\circ} \mathrm{C}$ fuel temperature and down to 0.3 bar absolute gas pressure, none of the tested fuels were found to spontaneously vaporize; all observed spray formations being a gradual evolution. Increasing the gas pressure at any given fuel temperature, leads to an increase in the boiling temperature of all components of that fuel and, hence, diminishes these effects.
\end{abstract}

\section{INTRODUCTION}

In the quest for ever more fuel efficient and lower pollution-emitting internal combustion spark ignition engines, a large emphasis world-wide has recently been put on Direct Injection Spark Ignition (DISI) engine research. In such an arrangement a metered amount of fuel is injected directly into the combustion chamber either during the induction stroke to maximize the air/fuel mixing time or during the compression stroke to promote charge stratification and direct a charge of 'appropriate' air/fuel ratio to the vicinity of the spark plug at time of ignition. Either strategy relies on the spray formation and break up to ensure adequate and appropriate mixing and charge direction. Hence knowledge of the factors affecting the spray development and the effects of these factors are important in the advancement of this engine technology. The very different in-chamber gas pressure conditions which prevail at the different injection timings, along with the variety of engine operating temperatures (from cold-start to heat-sink periods), affect the fuel spray to different extents depending on the composition of the fuel. This has particular bearings on engine research where single-component fuels or special blends of hydrocarbons are often used to replicate pump fuels. Although some information exists in the literature regarding the effect of these operating parameters on pressure-swirl injectors, e.g. [1, 2], no detailed data exist in the open literature which demonstrate the effect of these parameters on next generation multi-hole injectors for DISI engines. This work seeks to identify and quantify the effects of fuel temperature and gas pressure into which the fuel is injected for a variety of singlecomponent, model and pump fuels on the spray development for a multi-hole DISI engine injector.

\section{EXPERIMENTAL ARRANGEMENT}

The experiments were carried out in the Fuel System Test Facility (FSTF) at University College London (UCL). Two quiescent pressure chambers were used: a cylindrical and an octagonal one. A schematic diagram of the cylindrical pressure chamber showing the common mounting and instrumentation is given in Figure 1. The injector used for this investigation has been designed to produce six individual asymmetric plumes and it was mounted on the chambers at an angle of $19^{\circ}$ (with 
respect to the vertical axis of the chamber) to optimize the visualization of the asymmetric spray as viewed from the side. The injector mounting along with a schematic of the spray is shown in Figure 2. More details on the injector configuration and spray orientations will be presented later in this section.

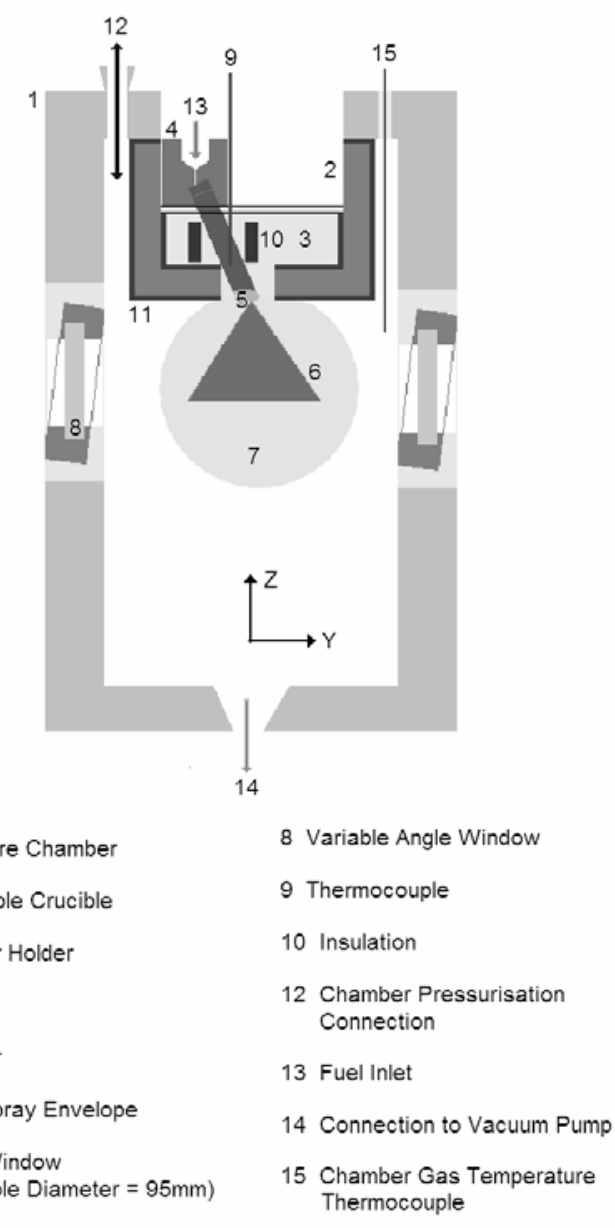

Figure 1. Schematic of Pressure Chamber.

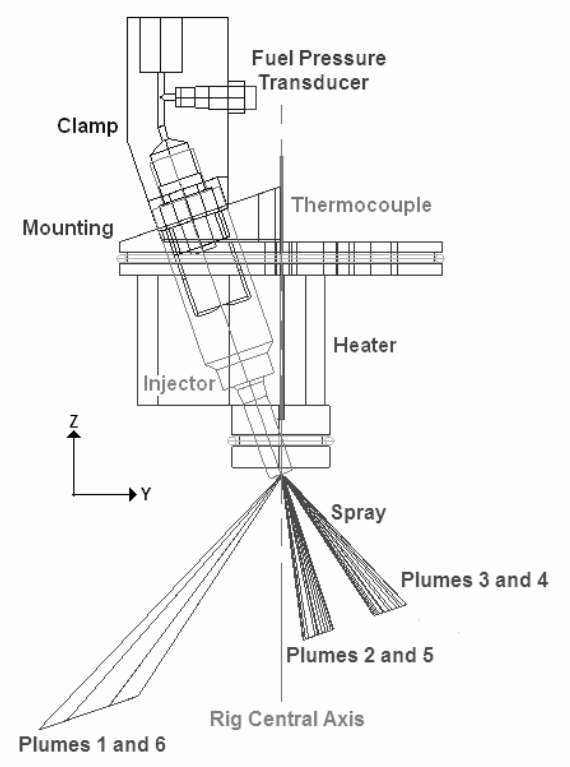

Figure 2. Injector Mounting Model.
Figure 3 shows the mounting and injector superimposed on a photograph of the cylindrical pressure chamber to illustrate the mounting position. The octagonal chamber is shown in Figure 4 . Both chambers were serviced by the same facilities and instrumentation and extensive tests were carried out on the octagonal chamber to ensure consistency of baseline results with those obtained in the cylindrical chamber. Chamber purging, as well as evacuation, was provided by a large liquid ring vacuum pump linked to a water/fuel separator used to expel fuel vapor. Fuel pressure was maintained constant for all presented experiments at 150 bar, pressurization being provided by a Haypac GX30 pneumatic-hydraulic piston ram pump. The fuel pressure was monitored by a Kistler 4065A200A2 pressure transducer to ensure consistency throughout all experiments.

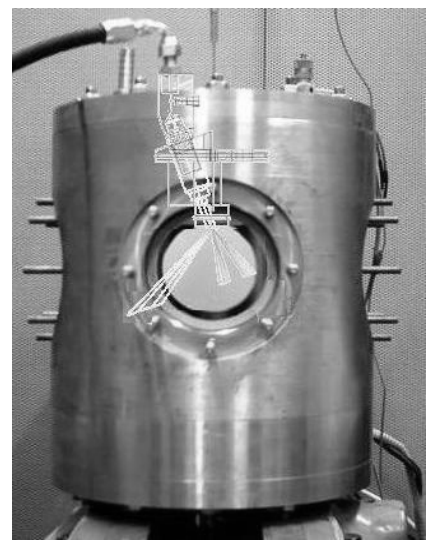

Figure 3. Cylindrical Pressure Chamber.

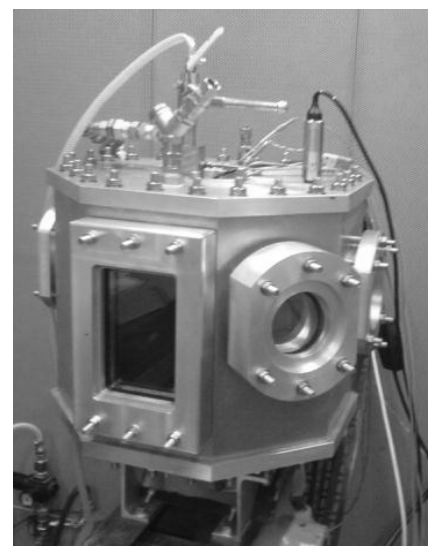

Figure 4. Octagonal Pressure Chamber.

The fuel spray was recorded using a Photron APX highspeed digital video camera. For the majority of tests presented in this paper, a Nikon AF Micro Nikkor $60 \mathrm{~mm}$ 1:2.8D lens was used at an f-stop of 2.8. The frame rate was set at 9,000 frames per second to represent one image at each crank angle degree for an engine running at 1500 RPM and giving a resolution of $640 \times 480$ pixels. The shutter was programmed to be open for $1 \mu \mathrm{s}$ at the same point in each frame. For the high-magnification, high-speed recording of the spray emanating from the injector nozzle, an Infinity Optics K2 lens was attached to the camera and the frame rate was increased to 50,000 
frames per second with a constantly open shutter. In all cases the spray was backlit using a Multiblitz Variolite 500 photographic flash-lamp, the light from which was diffused through a pair of semi opaque Perspex sheets. The injection timing and duration, which was held constant at $2 \mathrm{~ms}$ pulse-width to capture initial, steadystate and end of injection spray characteristics, as well as lighting and camera triggering pulses, were produced and controlled by an AVL 427 Engine Timing Unit (ETU). The principal rig systems are shown in Figure 5.

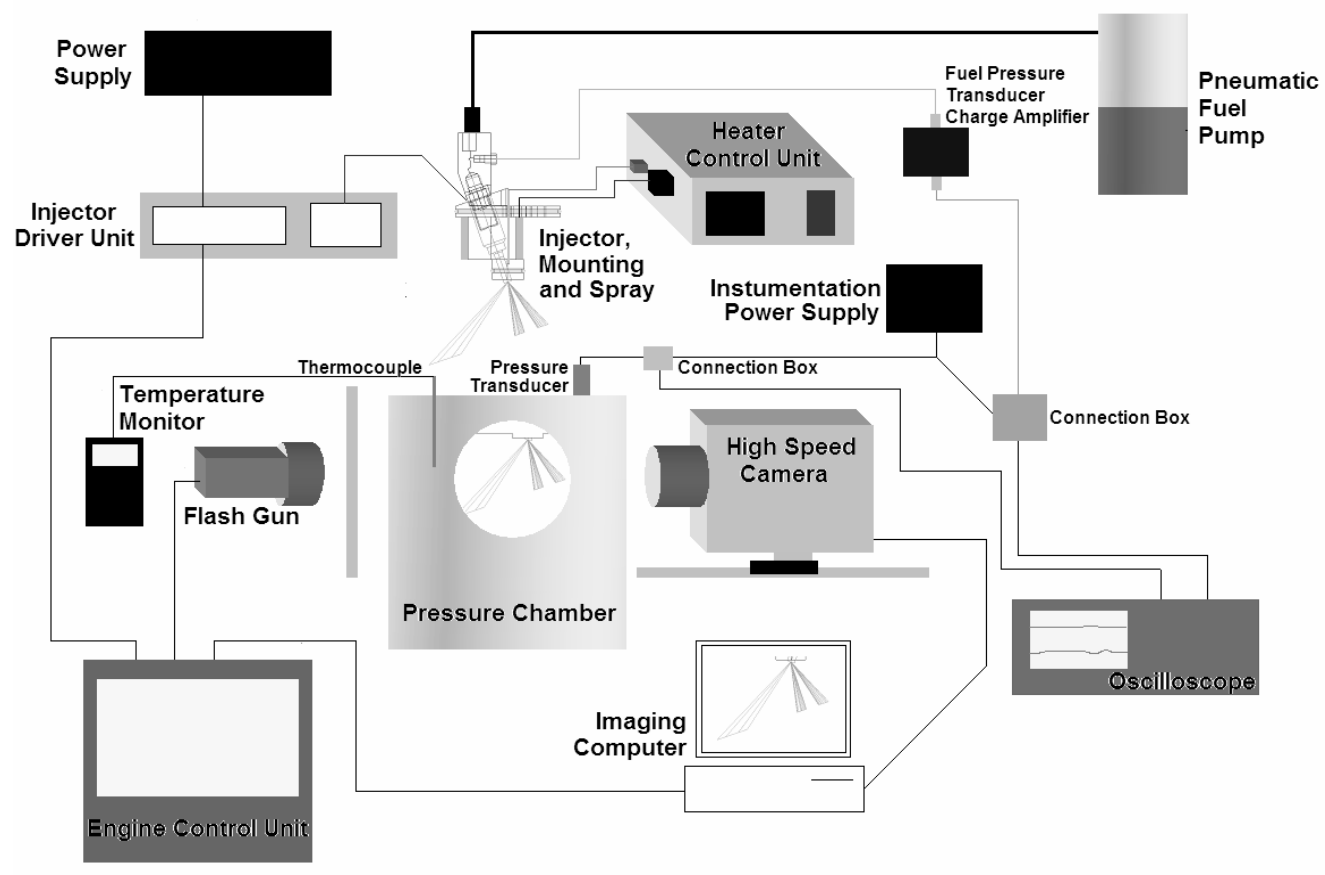

Figure 5. Schematic of Main Rig Connections.

The injector used for this investigation has been designed to produce six individual plumes. Imaging of the spray was carried out from a number of angles to show different features of the spray. These imaging directions are illustrated in Figure 6. The corresponding views were named 'Side', 'Angle', 'End' and 'Base'. The base view is equivalent to the view through the piston crown in an optical engine. Most of the results presented in this paper are based on the side view and hence it should be borne in mind that due to the back-lighting technique employed, each imaged jet is the superposition of two liquid jets. For reasons of confidentiality, no further details regarding the injector manufacturer, the injector's actuation mechanism, or its internal and external geometry can be divulged.

The injector body was heated in its mounting to replicate injector and fuel system in-situ heating in an engine. An Omega MB-1 $150 \mathrm{~W}$ band heater around the injector mounting provided the heating whilst a thermocouple sensor (installed as close to the injector tip as could be managed) provided feedback to a Desin BS-1000 temperature controller. It should be clearly noted here that the term 'Fuel Temperature' used in this paper corresponds to the temperature reading of this thermocouple, i.e. the temperature of the injector as close to the injector tip as possible, not the temperature of the fuel itself. This should always be borne in mind during the interpretation of results presented later. The heating arrangement was selected in order to simulate control of the fuel temperature in the injector by, essentially, only controlling the engine-head temperature in a real DISI engine. The fuel temperature was varied from $20{ }^{\circ} \mathrm{C}$ to $180{ }^{\circ} \mathrm{C}$ to replicate typical engine-head temperatures, as well as in-cylinder extremes.

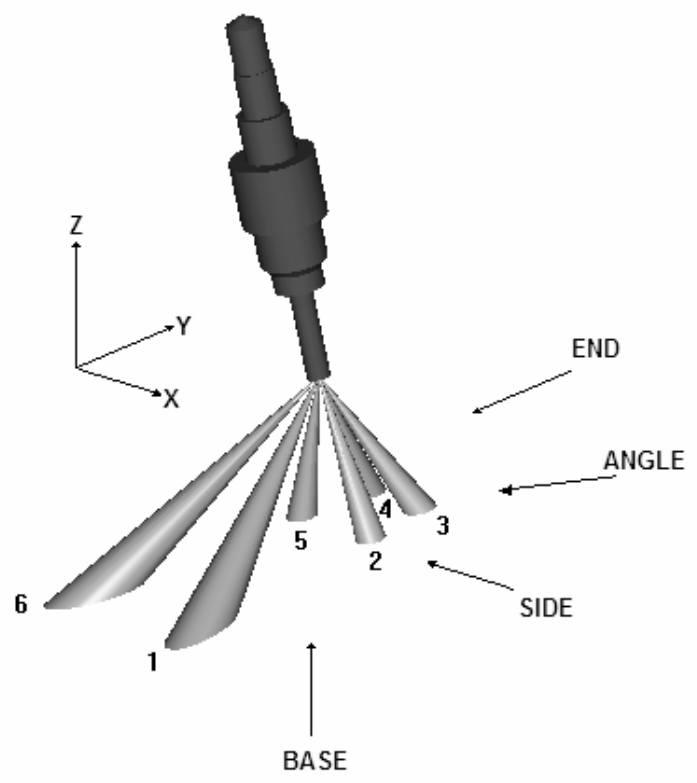

Figure 6. Designation of Spray Views. 
With reference to the designated views in Figure 6, Figure 7 shows typical images from each of the imaging directions for the spray as produced by the injector at a fuel temperature of $20^{\circ} \mathrm{C}$ and a gas pressure of $1.0 \mathrm{bar}$ absolute. The images are captured at $777 \mu$ s After the Start Of Injection (ASOI - the time interval after the trigger signal is sent to the injector driver). Note that for the side, angle and end views the spray is back-lit and hence it is imaged as a dark shadowgraph against a light background. For the base view the lighting is from the side of the spray and hence the spray is visualized by light scattering against a dark background.
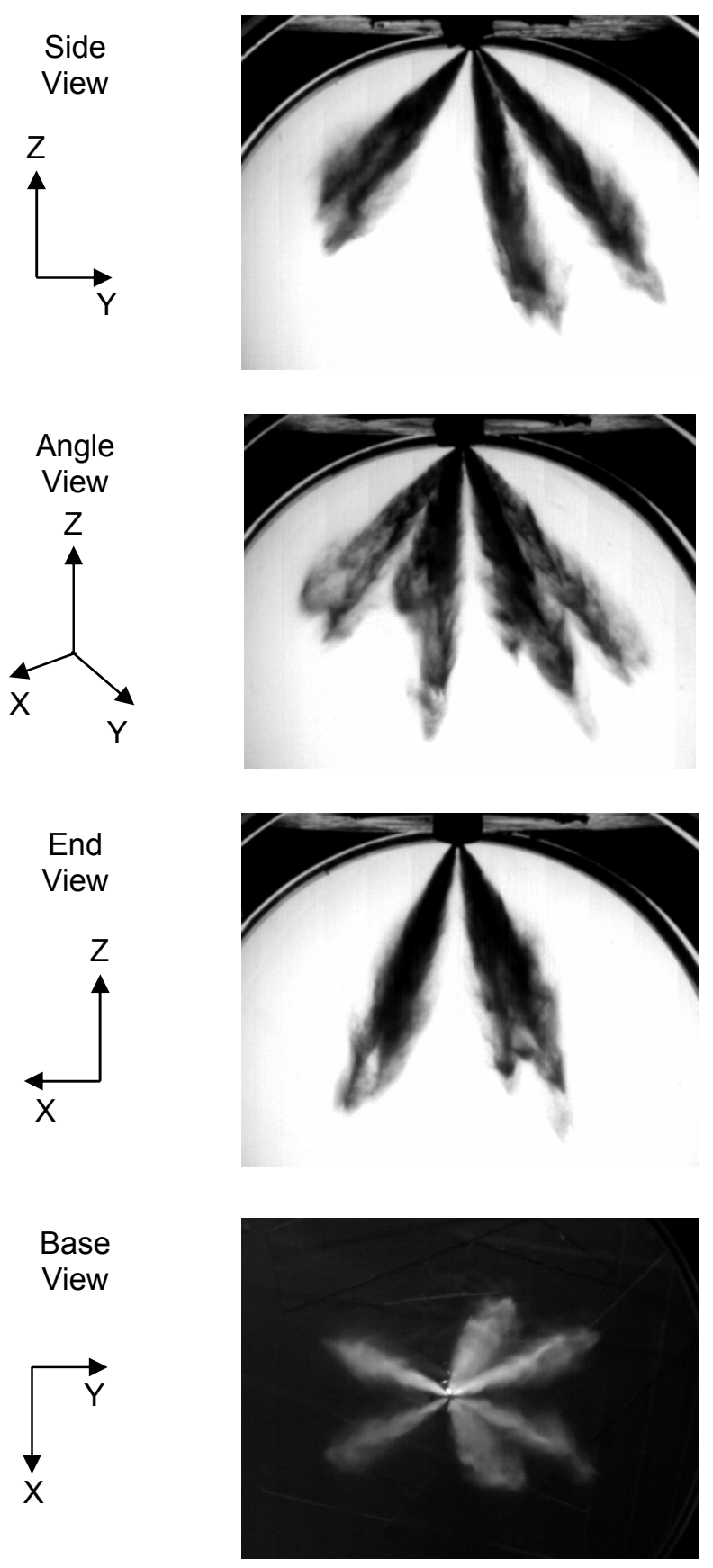

Figure 7. Typical Spray Images for Fuel 1 (Standard Gasoline) at $20^{\circ} \mathrm{C}$ Fuel Temperature, 1.0 bar Gas Pressure.

\section{TEST MATRIX}

The injector body was heated to temperatures of 20,50 , 90,120 and $180{ }^{\circ} \mathrm{C}$ on the assumption that given sufficient sink time (typically $1 / 2$ hour) and for injection frequencies of less than $1 \mathrm{~Hz}$, the fuel temperature would be that of the injector body. Due to practical limitations the chamber gas temperature was monitored but was not controlled beyond that of the ambient room temperature. All experiments for the current paper were conducted at a chamber gas temperature of between 23 and $28{ }^{\circ} \mathrm{C}$. No gas cooling or heating was observed during the tests due to the injection process and vaporization of fuel.

Tests were carried out at chamber gas pressures of 1.0, 0.5 and 0.3 bar absolute to mimic engine in-cylinder pressures at timing of typical injection strategies for 'homogeneous' engine operation mode, i.e. for injection during the intake stroke of a DISI engine for wide-openthrottle or part-load conditions. The chamber was purged after every 20 injections to prevent obscuration of the windows.

A total of six different fuels were tested over the pressure and temperature ranges indicated above, as listed in Table 1. These included "Pura" gasoline which was marketed in the Netherlands until 2004 and has a relative preponderance of light components, referred to as 'Standard' gasoline thereafter in this paper. This was used both with and without the normal gasoline additive treatment (Fuel 5 and Fuel 1, respectively). To contrast this, a special bespoke 'heavy' gasoline was tested with a preponderance of heavier components (Fuel 2). A multi-component model fuel was also tested. This model fuel had been designed to mimic the distillation properties of a full boiling range gasoline fuel, but it was free from aromatics so that it would not fluoresce under laser illumination, for quantitative measurements of concentration with Laser Induced Fluorescence (LIF) techniques when appropriate individual tracer components would be added to it [3]. The fuel matrix was completed by the single-component species iso-octane and $n$-pentane that have very different boiling points (Fuel 4 and Fuel 6, respectively).

The Reid Vapor Pressure (RVP) for all the tested fuels is shown in Table 1. This is a standard measurement of fuel volatility at $37.8{ }^{\circ} \mathrm{C}$ [4]. Furthermore, The ASTM distillation curve is shown for all the fuels in Figure 8 . The concept of a distillation curve is somewhat meaningless for single-component fuels since they boil completely at a single temperature, hence the vertical lines in Figure 8 for iso-octane (Fuel 4) and n-pentane (Fuel 6). ASTM distillation curves and RVPs represent the most common metrics in the description of the volatility characteristics of fuels, not least because they have been related to drivability and evaporative emissions respectively and hence appear in fuels specifications. However, their usefulness in describing the characteristics of sprays is less clear. 
Table 1. Fuels Tested.

\begin{tabular}{|c|c|c|c|}
\hline $\begin{array}{c}\text { Fuel } \\
\text { No }\end{array}$ & Fuel Type & $\begin{array}{c}\text { Density at } 2{ }^{\circ} \mathrm{C} \\
{\left[\mathrm{g} / \mathrm{cm}^{3}\right]}\end{array}$ & $\begin{array}{c}\text { Reid Vapor } \\
\text { Pressure [bar] }\end{array}$ \\
\hline 1 & $\begin{array}{c}\text { 'Standard' Gasoline } \\
\text { without Additives }\end{array}$ & 0.720 & 0.56 \\
\hline 2 & $\begin{array}{c}\text { 'Heavy' Gasoline } \\
\text { without Additives }\end{array}$ & 0.766 & 0.67 \\
\hline 3 & $\begin{array}{c}\text { Model Fuel for Use } \\
\text { with LIF }\end{array}$ & 0.681 & 0.79 \\
\hline 4 & iso-Octane & 0.692 & 0.12 \\
\hline 5 & $\begin{array}{c}\text { 'Standard' Gasoline } \\
\text { with Additives }\end{array}$ & 0.719 & 0.56 \\
\hline 6 & n-Pentane & 0.626 & 1.08 \\
\hline
\end{tabular}

Table 2. Bubble Point and Dew Point Pressures.

\begin{tabular}{|c|c|c|c|c|c|c|c|c|c|c|}
\hline \multirow{2}{*}{$\begin{array}{c}\text { Fuel } \\
\text { No }\end{array}$} & \multicolumn{3}{|c|}{ Bubble Point Pressure [bar] } & \multicolumn{4}{c|}{ Dew Point Pressure [bar] } \\
\cline { 2 - 11 } & $20^{\circ} \mathrm{C}$ & $50^{\circ} \mathrm{C}$ & $90^{\circ} \mathrm{C}$ & $120^{\circ} \mathrm{C}$ & $180^{\circ} \mathrm{C}$ & $20^{\circ} \mathrm{C}$ & $50^{\circ} \mathrm{C}$ & $90^{\circ} \mathrm{C}$ & $120^{\circ} \mathrm{C}$ & $180^{\circ} \mathrm{C}$ \\
\hline 1 & 0.3 & 0.8 & 2.4 & 4.5 & 13.0 & 0.0 & 0.1 & 0.5 & 1.3 & 5.9 \\
\hline 2 & 0.4 & 1.0 & 2.6 & 4.5 & 11.6 & 0.0 & 0.0 & 0.3 & 0.8 & 3.8 \\
\hline 3 & 0.5 & 1.2 & 3.0 & 5.4 & 13.8 & 0.0 & 0.1 & 0.4 & 1.1 & 5.1 \\
\hline 4 & 0.1 & 0.2 & 0.8 & 1.8 & 6.3 & 0.1 & 0.2 & 0.8 & 1.8 & 6.3 \\
\hline 5 & 0.3 & 0.8 & 2.4 & 4.6 & 13.2 & 0.0 & 0.1 & 0.5 & 1.3 & 6.0 \\
\hline 6 & 0.6 & 1.6 & 4.7 & 9.1 & 26.4 & 0.6 & 1.6 & 4.7 & 9.1 & 26.4 \\
\hline
\end{tabular}

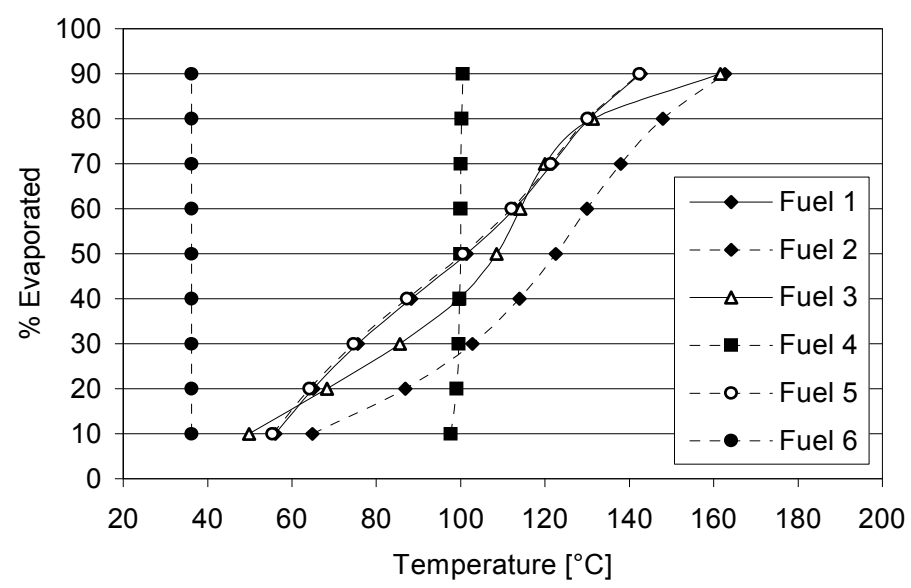

Figure 8. ASTM Distillation Curves.

Bubble point and dew point pressures were calculated for each fuel at various temperatures, as shown in Table 2 , using a Redlich-Kwong equation of state [5] based on UNIFAC method coefficients for each species identified on the gas chromatograph of each of the fuels. The bubble point of a liquid refers to the pressure, below which bubbles will form at the given temperature. Likewise the dew point is the pressure below which the fluid is in vapor state at the given temperature. An increase in pressure over the dew point leads to the formation of liquid droplets at this temperature [6].
Clearly the bubble and dew point pressures are the same for single-component fuels. The bubble point is likely to be indicative of conditions under which light ends begin to flash off in a fuel spray, whereas the dew point may be loosely indicative of the final evaporation of heavy ends from a droplet. It should be noted, however, that the bubble point and dew point are equilibrium concepts and during a transient process heat and mass transfer effects will complicate the picture. Their influence is expected to be significant for spray evaporation in an engine. It should also be noted that the bubble point pressure of iso-octane is significantly less than the gasoline fuels throughout the whole temperature range. This is important in the interpretation of results that are presented later in this paper.

\section{IMAGE PROCESSING}

The majority of experiments were carried out in the cylindrical chamber, whilst imaging of the sprays from the base view, as well as all the tests with $n$-pentane, were carried out in the octagonal chamber. A total of 120 injection events were captured for each test condition, as well as a background set. Mean and RMS (Root Mean Square - standard deviation from the mean) images for each recorded time interval were calculated from the raw images. For measurement of spray penetration, all images were processed so that spray features could be identified. The background image for each imaging sequence was removed to account for differences in lighting over the run. Each image was then thresholded to leave a binary image. Due to the different angles at which each plume pair emerged from the nozzle tip, the image was required to be rotated to align each plume pair with the vertical axis. The rotated image was then 'scanned' to find the plume tip. The distance from the plume tip to the nozzle was scaled to calculate a plume pair length and graphs of penetration versus time were drawn for each case.

\section{RESULTS}

The spray development for a typical injection is shown in Figure 9 at a chamber gas pressure of 0.5 bar absolute and a fuel temperature of $20^{\circ} \mathrm{C}$. At this condition there is little difference between the sprays for the different fuels. Increasing the fuel temperature to $120{ }^{\circ} \mathrm{C}$ at $0.5 \mathrm{bar}$ causes a convergence of the spray plumes as illustrated in Figure 10. The combination of the right-hand plume pairs produces a single high-velocity penetrating central plume surrounded by a slower penetrating liquid cloud. Convergence, labeled 'spray collapse' due to the deviation from the 'normal' multi-plume form, is evident to a large extent for Fuels 1, 3 and 6 (standard gasoline, model fuel and $n$-pentane respectively) and to a lesser degree for Fuel 4 (iso-octane). This is due to the lower boiling points (of the lightest boiling fractions in the case of multi-component Fuels 1 and 3), and hence higher bubble point pressures of these fuels compared to Fuel 4. At later intervals ASOI, the spray produced by Fuel 6 (n-pentane) is the most vaporized, showing the least black area in and around the spray. 
Fuel
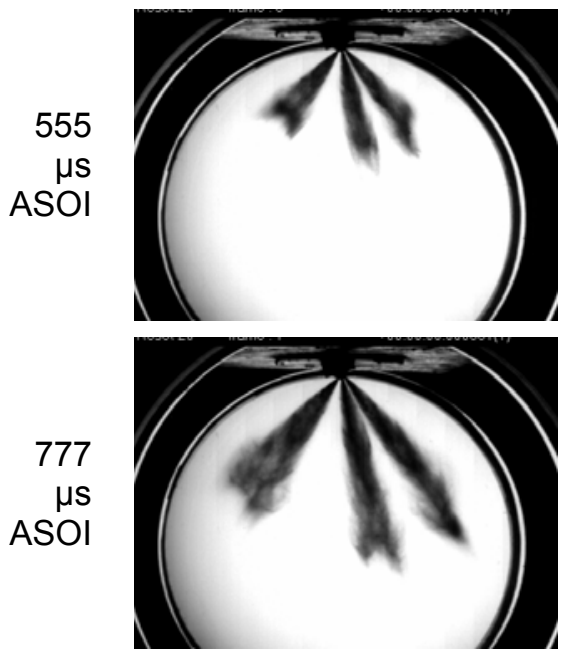

999

HS

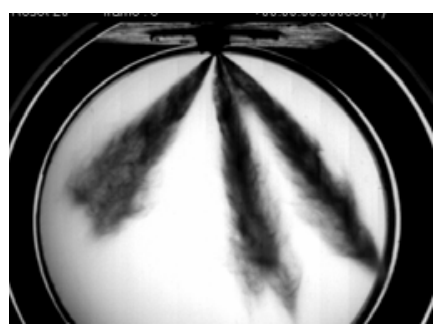

(model fuel)
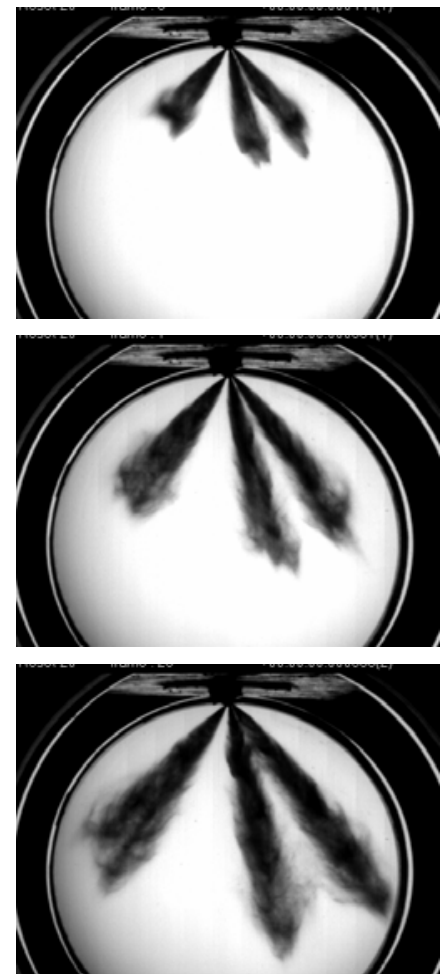

4

(iso-octane)
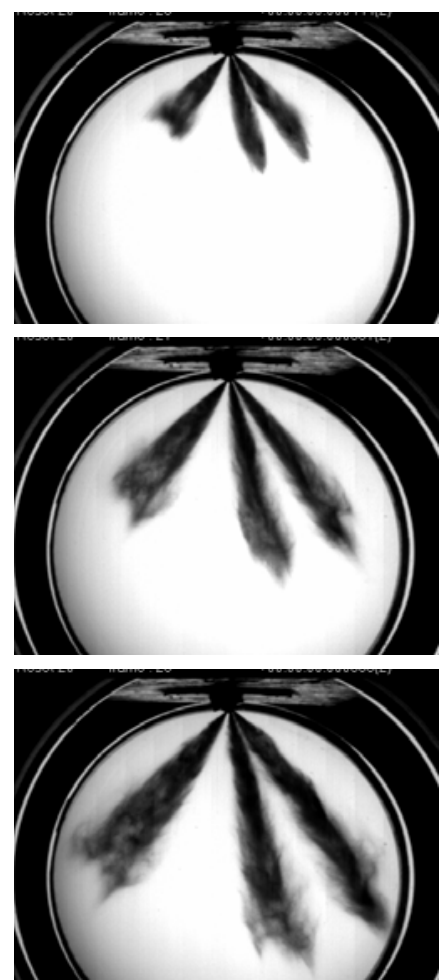

6

(n-pentane)
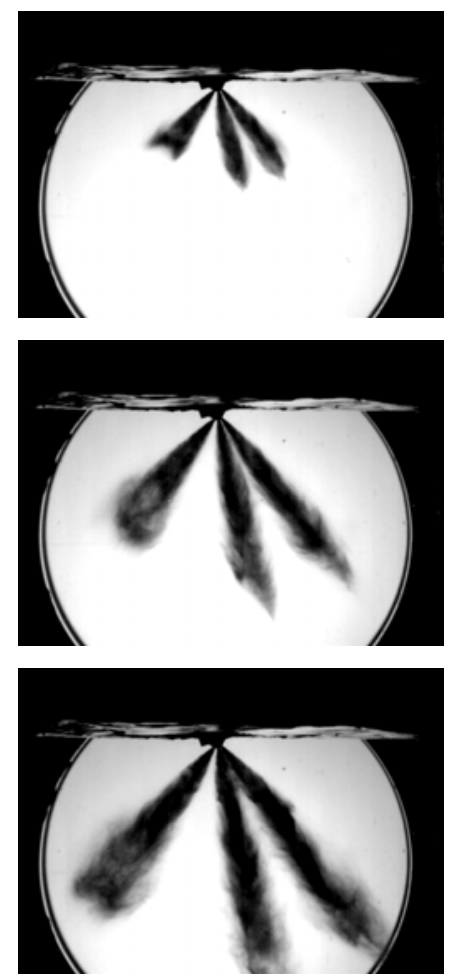

Figure 9. Spray Development: $20^{\circ} \mathrm{C}$ Fuel Temperature, 0.5 bar Gas Pressure, Side View.

Fuel

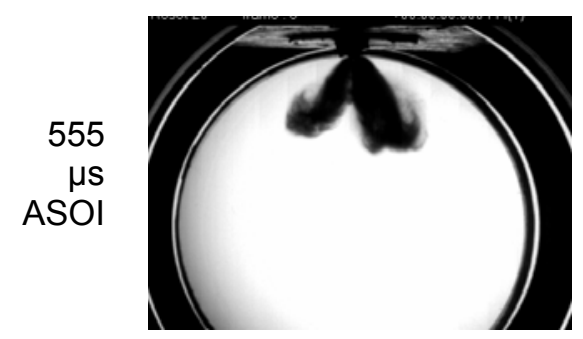

777

$\mu \mathrm{S}$
ASOI
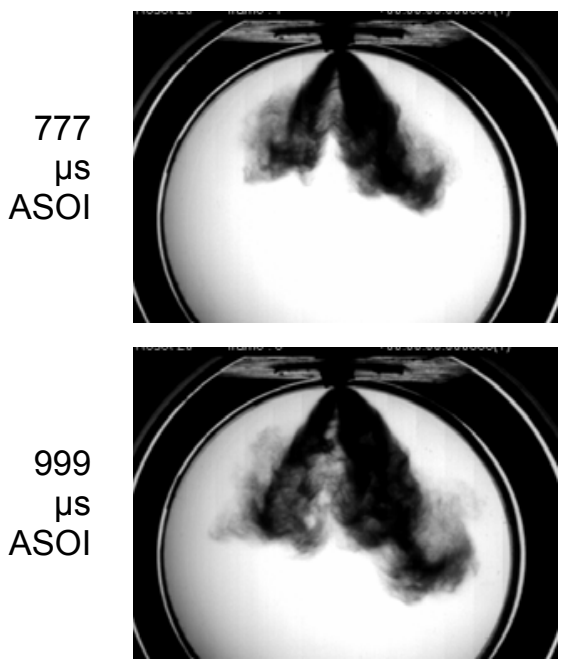

3

(model fuel)
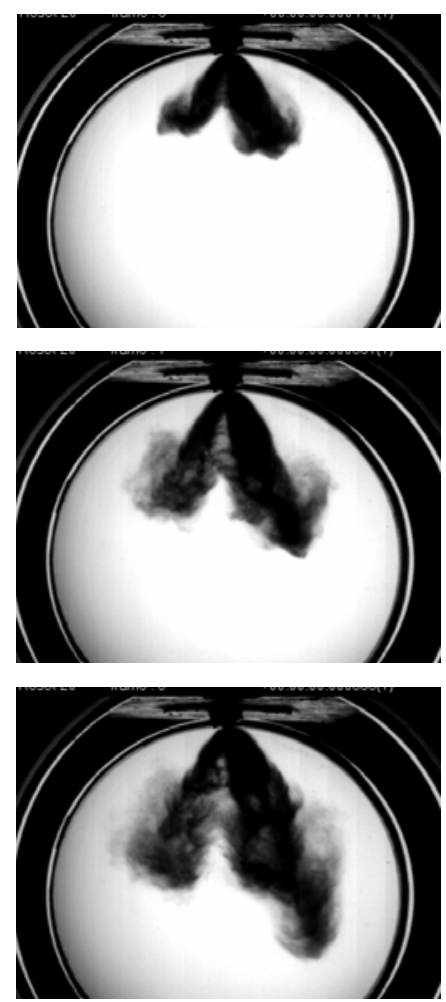

4

(iso-octane)
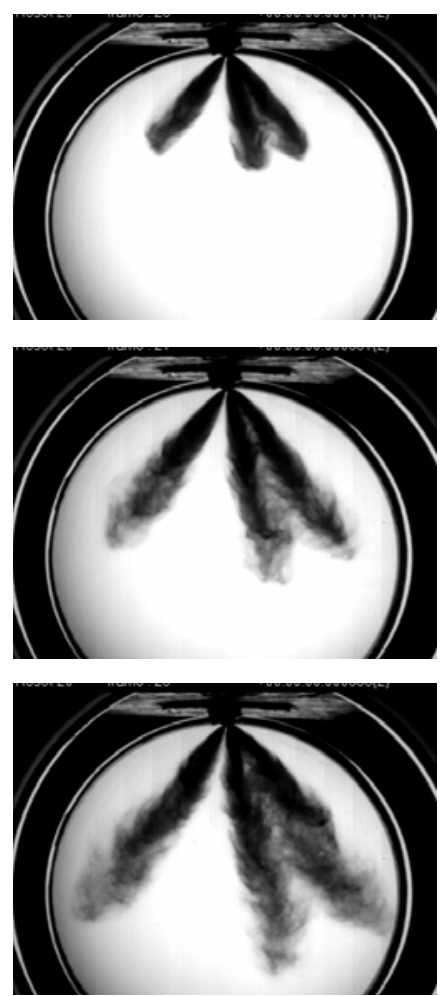

6

(n-pentane)
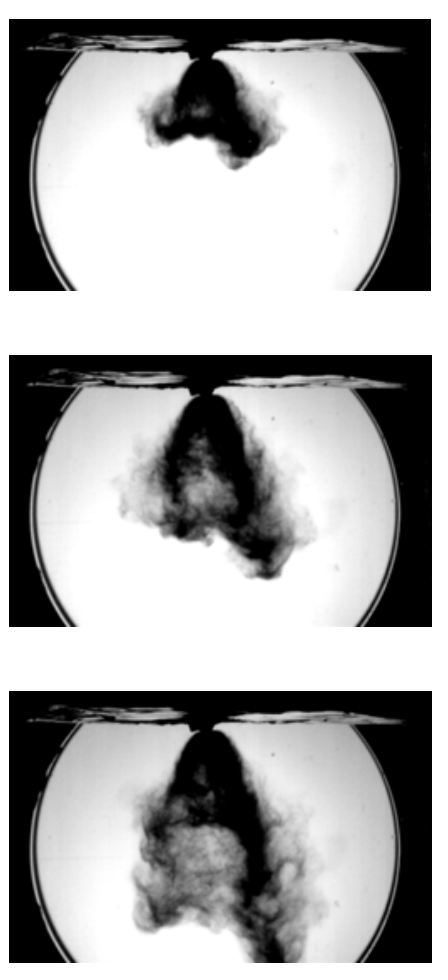

Figure 10. Spray Development: $120^{\circ} \mathrm{C}$ Fuel Temperature, 0.5 bar Gas Pressure, Side View. 
In order to appreciate the degree of collapse and for comparison with the 'normal' spray shown from all views in Figure 6, the collapsed spray is also shown from all views in Figure 11.
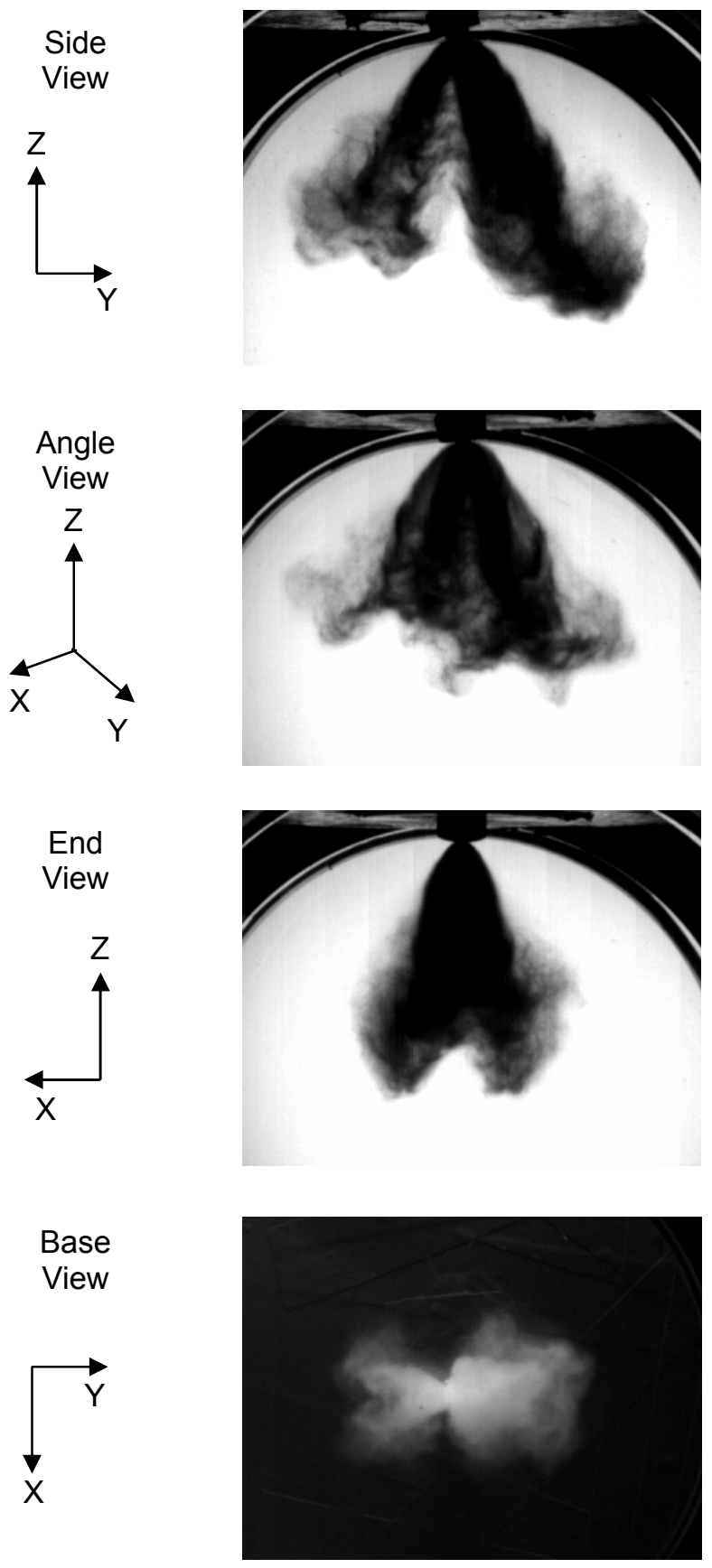

Figure 11. Typical Spray Images for Fuel 1 (Standard Gasoline) at $120^{\circ} \mathrm{C}$ Fuel Temperature, 0.5 bar Gas Pressure, $777 \mu \mathrm{s}$ ASOI.

The individual spray matrices shown in Figures 12-14 at $777 \mu \mathrm{s}$ ASOI for the tested range of fuel temperatures and gas pressures show the effect of these parameters on spray development. A decrease in pressure below 1.0 bar brings about an increase in penetration rate and a more collapsed spray form for all fuels at elevated temperatures. Iso-octane, which has the highest initial boiling temperature (and correspondingly lowest RVP) of all the fuels, is seen to collapse the least at elevated fuel temperature, reduced gas pressure conditions, whilst the other fuels are seen to show significant collapse at this condition. Increasing the fuel temperature at 1.0 bar gas pressure, causes some contraction of the sprays of those fuels with lower boiling points, in particular $n$ pentane in Figure 14, which shows a total combination of the closely spaced four plumes on the right of the image at $120{ }^{\circ} \mathrm{C}, 1.0$ bar. On the contrary, Fuel 4 (iso-octane) which has a boiling temperature of approximately $60{ }^{\circ} \mathrm{C}$ higher than that of $n$-pentane shows no collapse or convergence at this condition. Fuel 1 (standard gasoline) shows some drawing together of the far right plumes but the individual plumes are still very much distinguishable. At 0.5 bar gas pressure, all fuel types produce a 'normal' spray at fuel temperatures up to and including $50{ }^{\circ} \mathrm{C}$. A further increase in fuel temperature to $90^{\circ} \mathrm{C}$ produces no discernable change in the sprays of Fuel 4 (iso-octane, Figure 13), whilst those produced by Fuel 6 ( $n$-pentane, Figure 14) are seen to collapse at this condition. Fuel 1 (standard gasoline, Figure 12) produces sprays that show some convergence although collapse is not complete. At $120^{\circ} \mathrm{C}$ collapse is complete for Fuel 1 and remains complete for Fuel 6 . At this temperature Fuel 4 shows some convergence but incomplete collapse.

These general trends are confirmed in the mean images for each type of fuel for $20{ }^{\circ} \mathrm{C}$ fuel temperature, $1.0 \mathrm{bar}$ gas pressure in Figure 15 and for $120{ }^{\circ} \mathrm{C}$ fuel temperature, 0.5 bar gas pressure in Figure 16 for both the side and base views of the spray. At the spray collapse conditions in Figure 16, a semi-vortex structure can be seen to be established on the side of the collapsed plume, especially for Fuel 1 (standard gasoline). A similar vortex has been observed by several researchers, e.g. [1, 7, 8], for pressure-swirl atomizers at spray-collapse conditions, suggesting the presence of fuel vapor which is being entrained into the air flow under motion due to shearing along the combined spray plume boundary. The vortex is also evident for Fuel 6 ( $n$ pentane), but was more pronounced at the condition of $90{ }^{\circ} \mathrm{C}$ fuel temperature and 0.5 bar gas pressure, as shown in the instantaneous images of Figure 14. At the condition of $120{ }^{\circ} \mathrm{C}$ fuel temperature, 0.5 bar gas pressure, this vortex formation is less clear for $n$ pentane, probably because atomization and evaporation is much quicker on this occasion as the fuel is heated well beyond the conditions of its onset of spray collapse.

The RMS images for the same conditions to those of the mean images are also shown in Figures 15 and 16. For the non-collapse conditions in Figure 15, similar levels of RMS about the plume tips can be observed for all fuels. The scale has been normalized to the maximum value of RMS in these images. The maximum value was of the order $20-30 \%$ of the mean and this gives a measure of the observed 'variability'. For the collapse conditions in Figure 16 there is a similar level of maximum RMS about the plume tips for all fuels despite the large differences in spray formation. However, the regions of non-zero RMS are wider for the collapse conditions, especially around the periphery of the spray plumes. 
0.5 bar
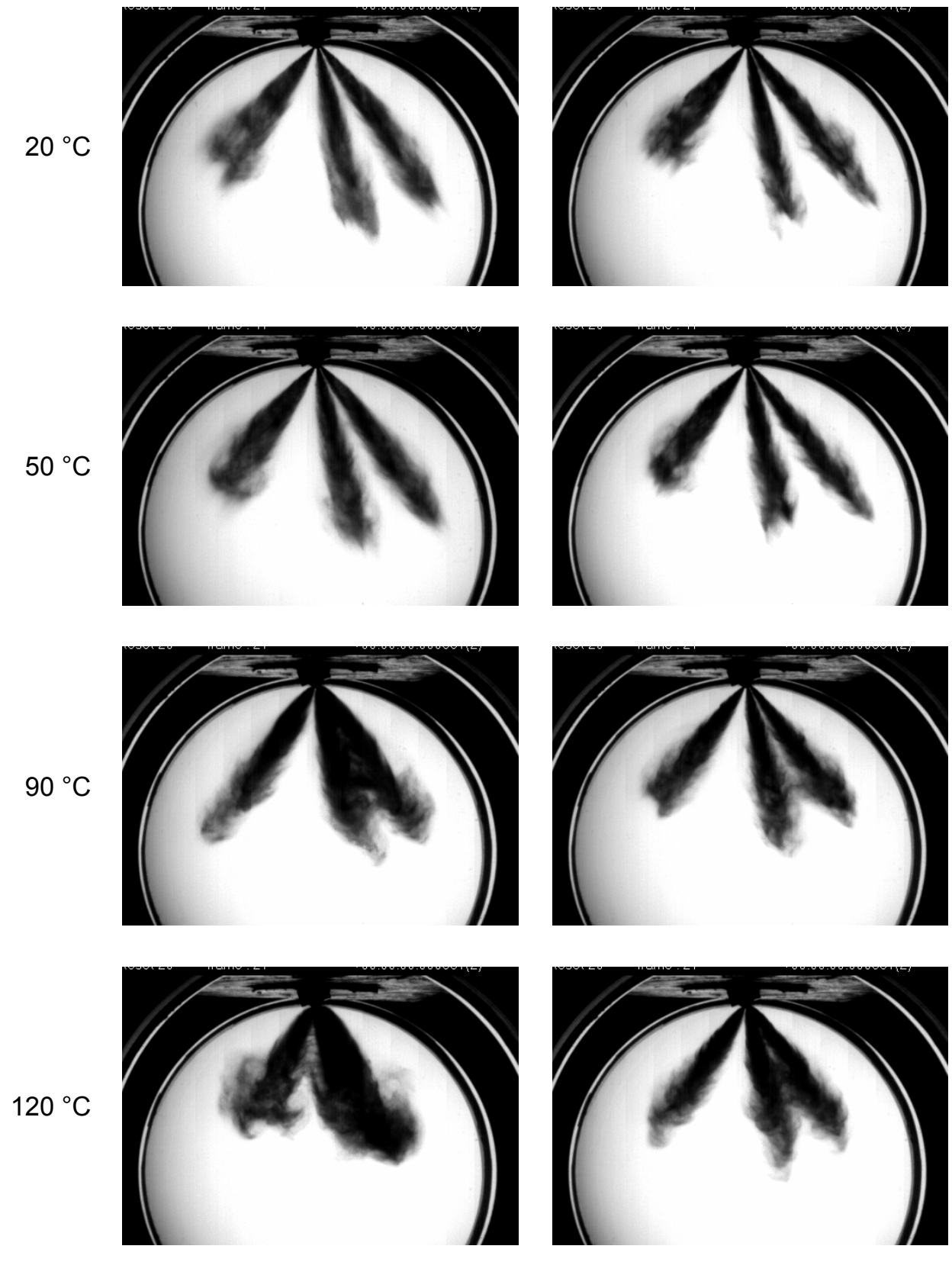

Figure 12. Spray Development: Fuel 1 (Standard Gasoline), 777 us ASOI, Side View. 
0.5 bar
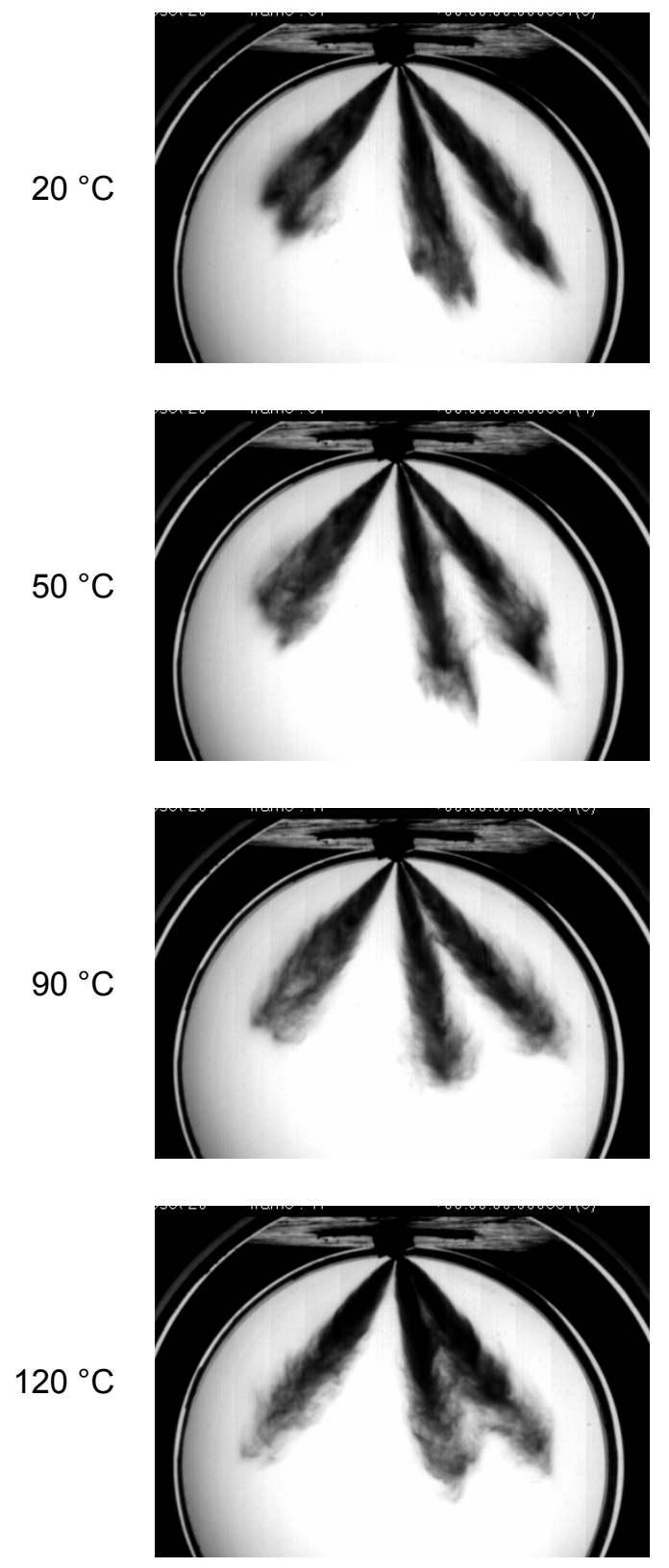

1.0 bar
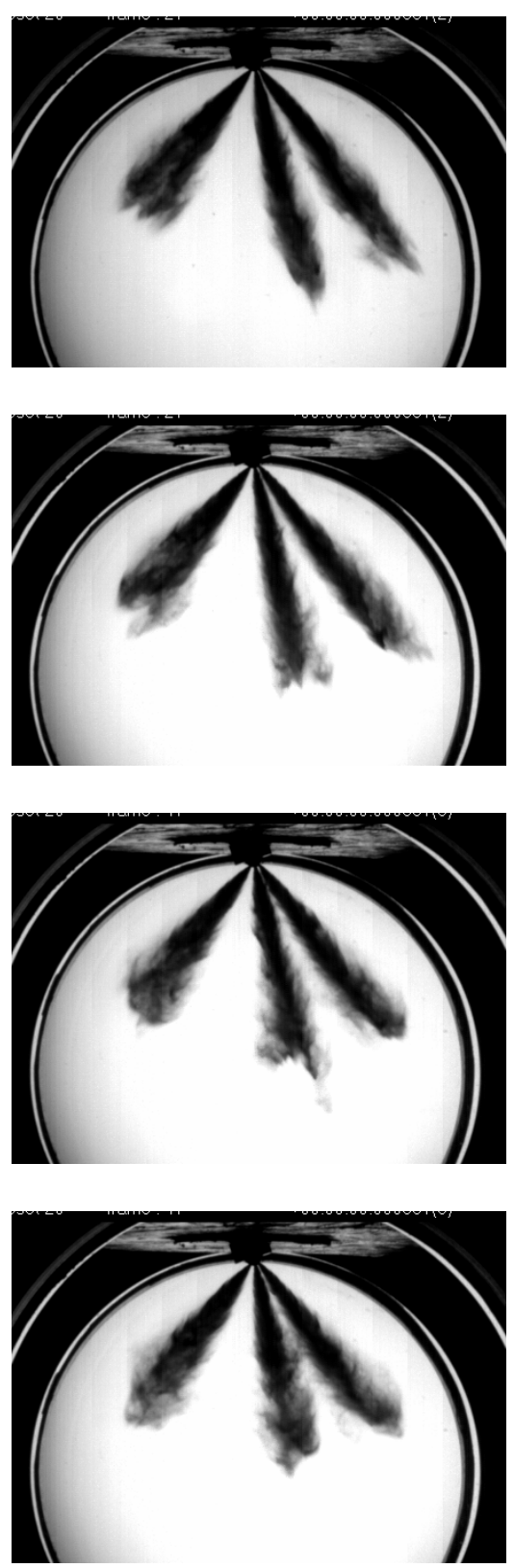

Figure 13. Spray Development: Fuel 4 (iso-Octane), 777 us ASOI, Side View. 
0.5 bar
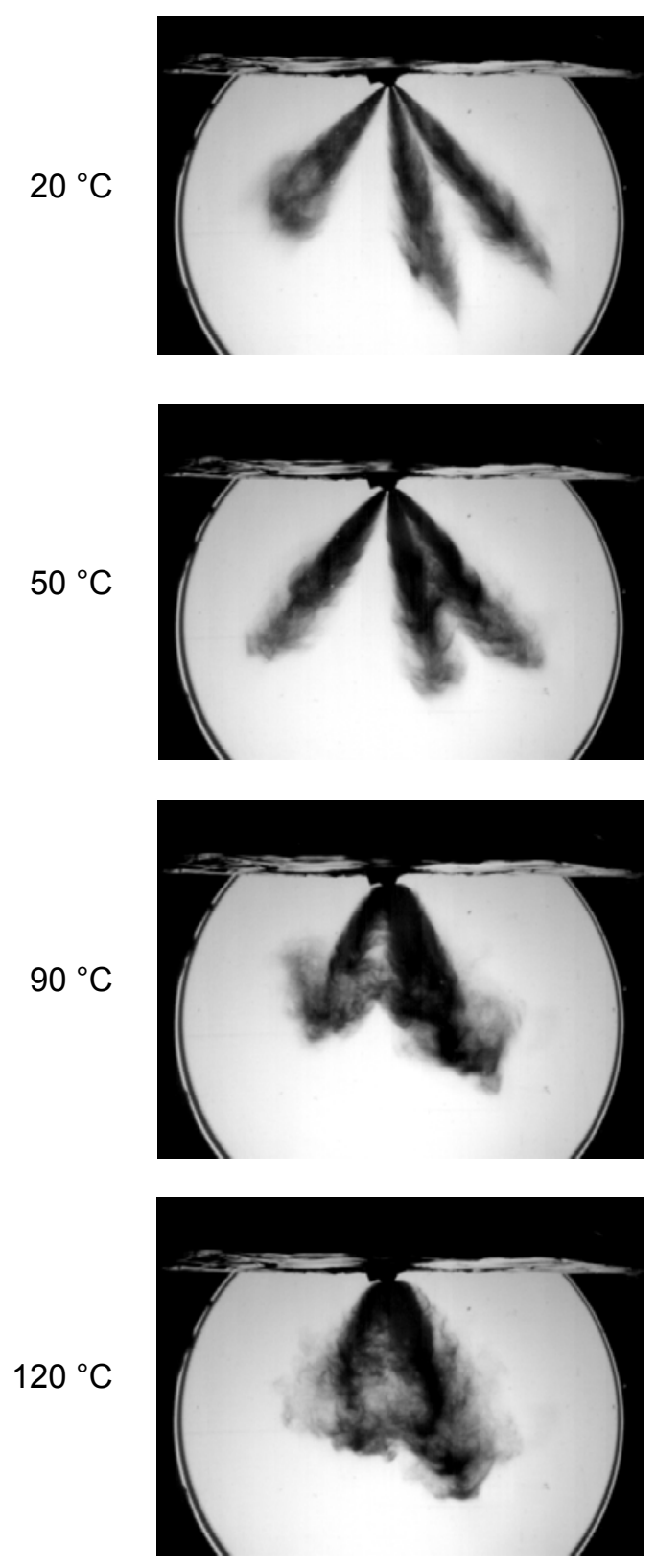

Figure 14. Spray Development: Fuel 6 ( $n$-Pentane), 777 us ASOI, Side View.
$1.0 \mathrm{bar}$
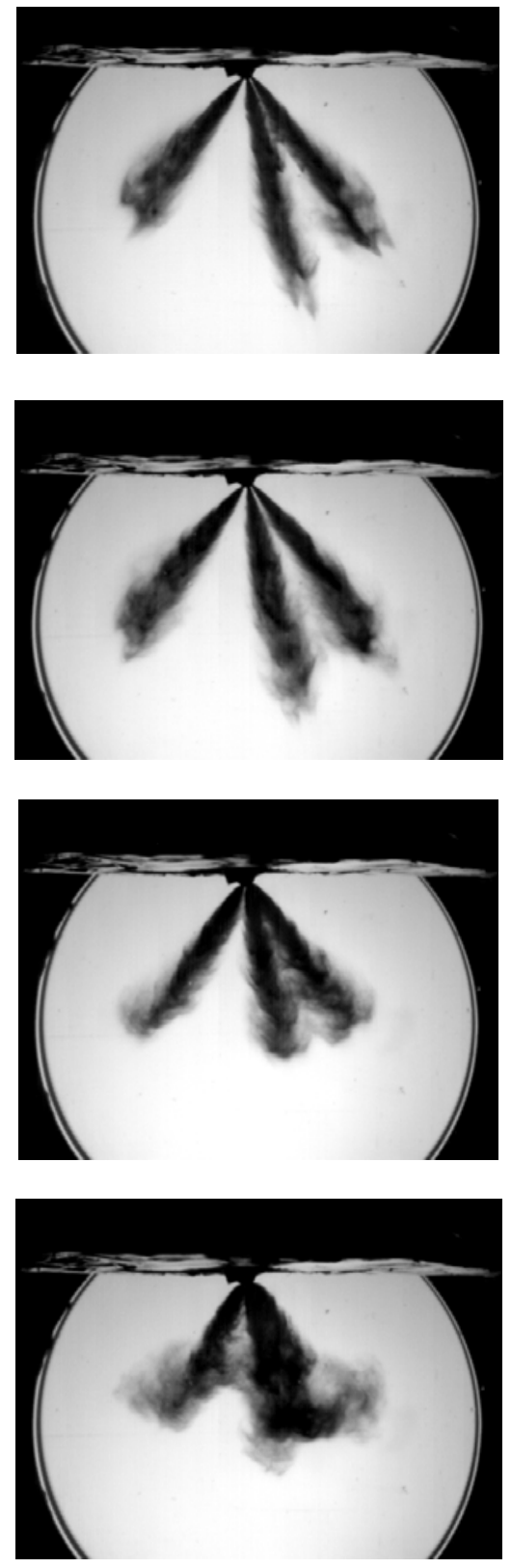
Fuel 1

(standard gasoline)
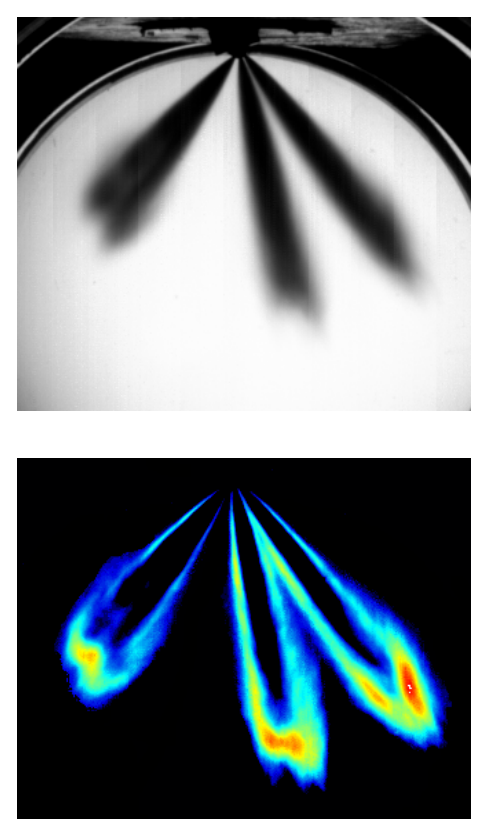

Side View RMS Image

Base View Mean Image
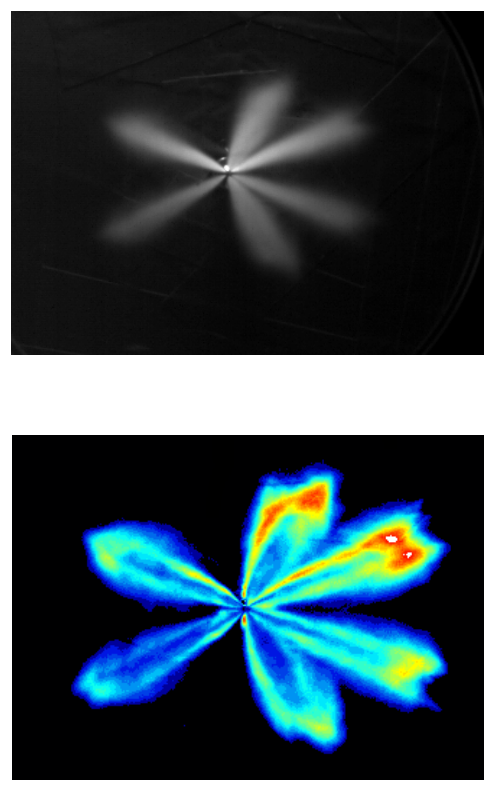

Fuel 4 (iso-octane)
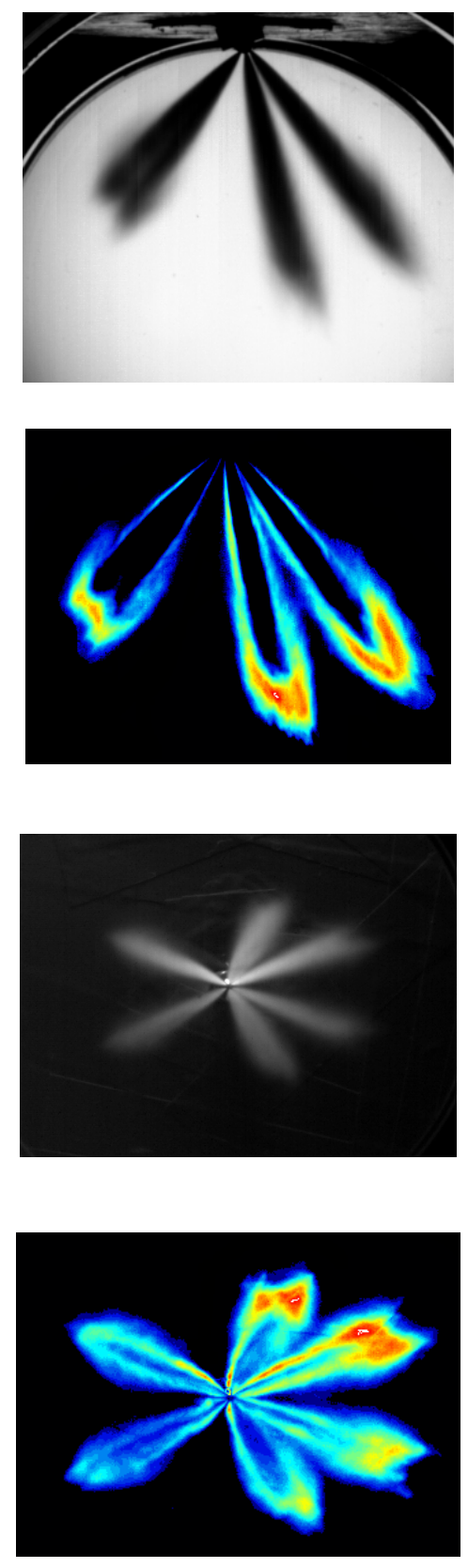

Fuel 6 (n-pentane)
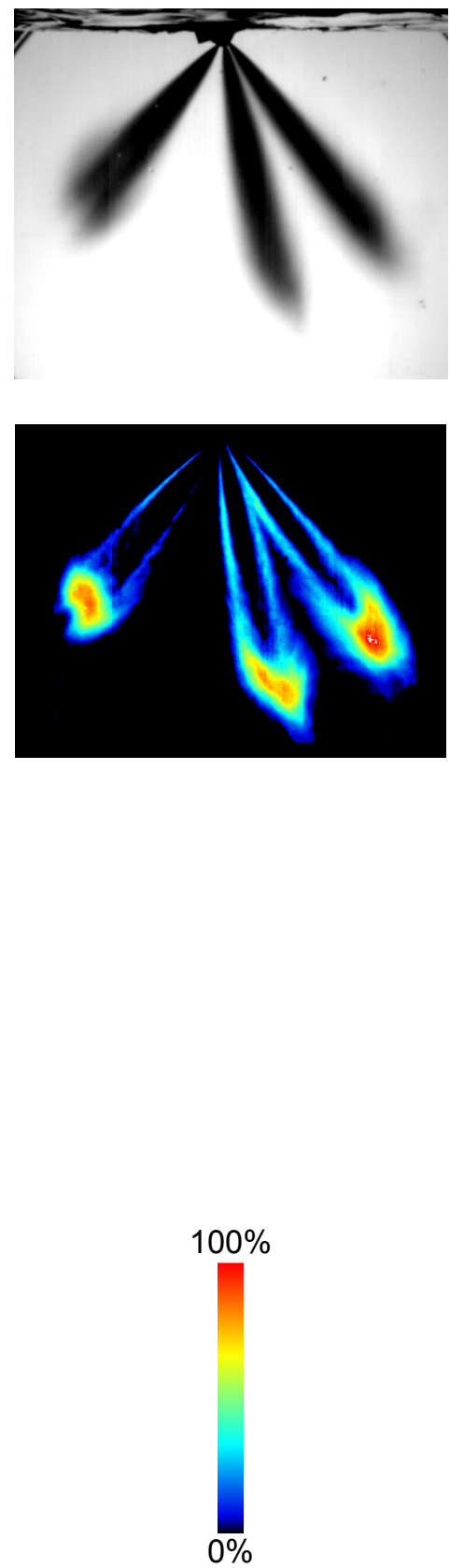

Figure 15. Mean and RMS Spray Images at $777 \mu$ s ASOI for $20^{\circ} \mathrm{C}$ Fuel Temperature, 1.0 bar Gas Pressure. 
Fuel 1

(standard gasoline)
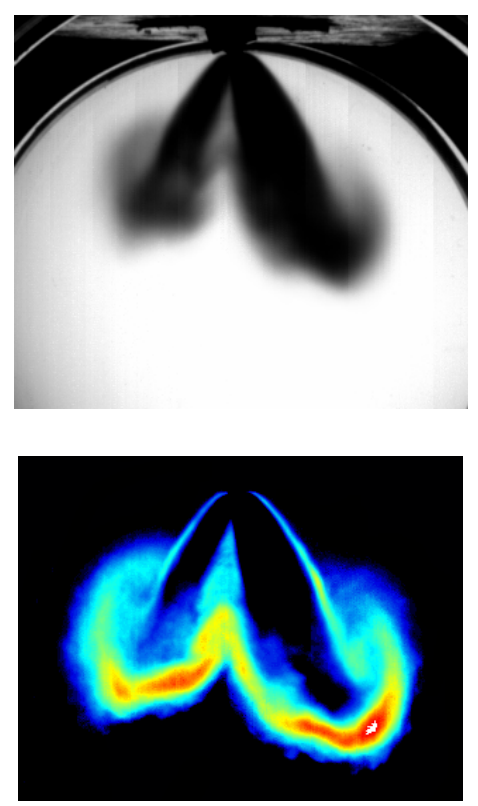

Side View RMS Image

Base View Mean Image
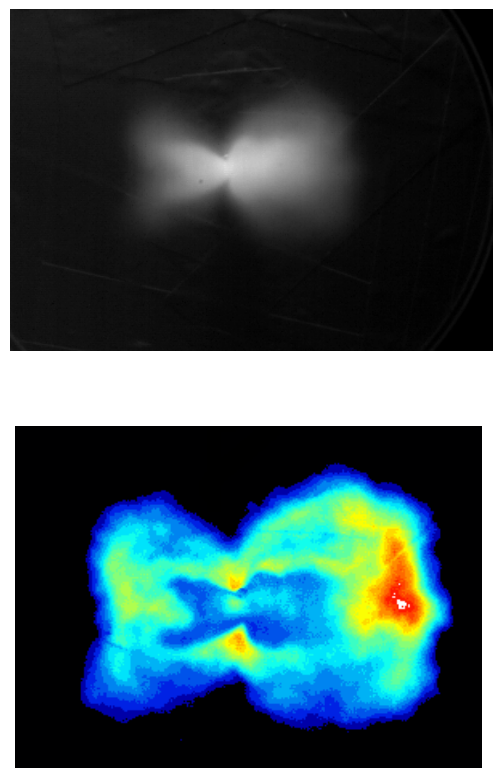

Fuel 4 (iso-octane)
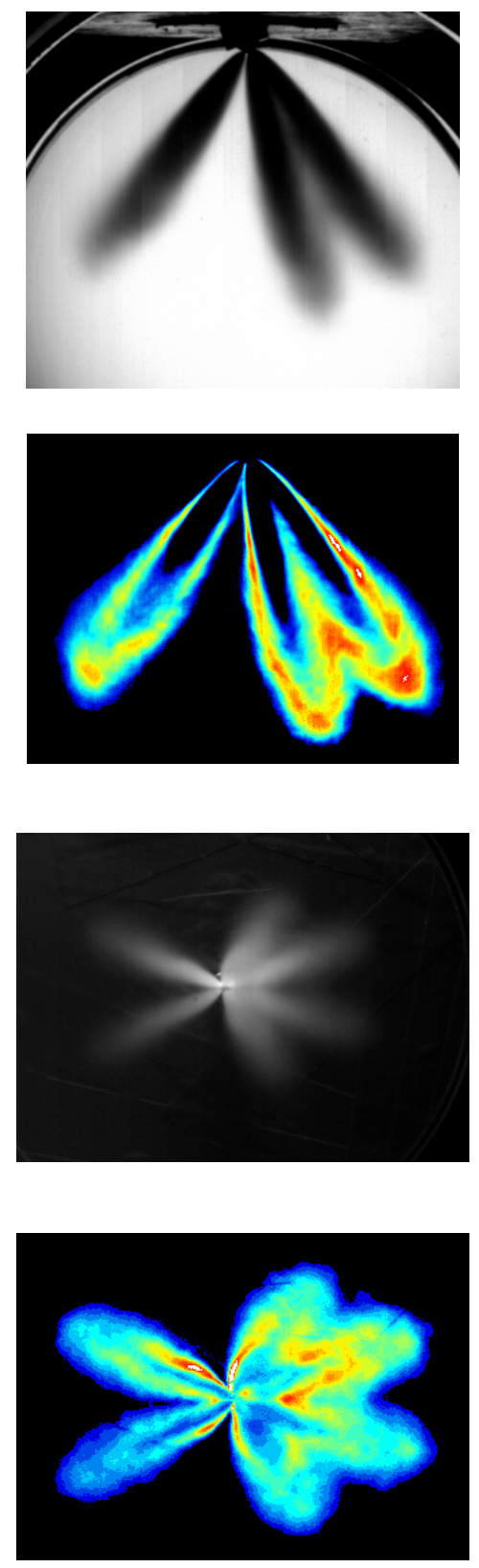

Fuel 6 (n-pentane)
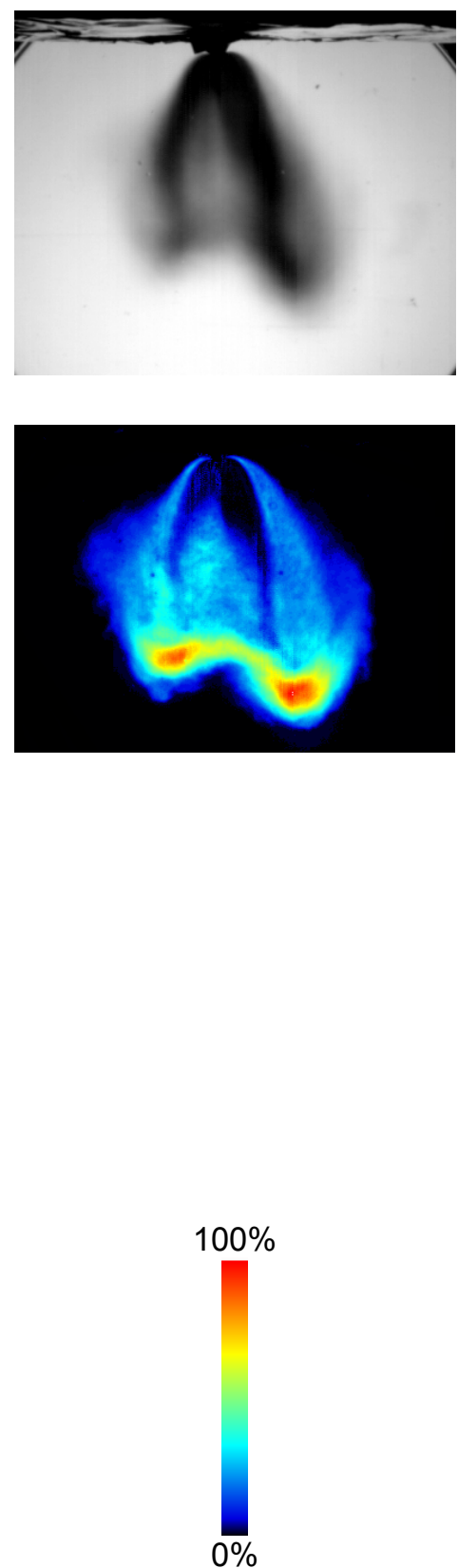

Figure 16. Mean and RMS Spray Images at $777 \mu$ s ASOI for $120^{\circ} \mathrm{C}$ Fuel Temperature, 0.5 bar Gas Pressure. 
In particular, for Fuel 6 ( $n$-pentane), the side view shows a wide area of RMS but with values very close to the bottom of the scale; the areas of high RMS are only localized close to the leading edge of the combined plume. This is probably related to the fact that as $n$ pentane has the lowest boiling point in comparison to the rest of the fuels tested and as it is heated to considerably above its nominal boiling temperature at this condition, atomization and evaporation is rapid and quite consistent throughout all the injection events recorded. Fuel 4 (isooctane) does not exhibit full collapse even at $120^{\circ} \mathrm{C}$ fuel temperature, 0.5 bar gas pressure in Figure 16 and exhibits similar levels of maximum RMS to those in Figure 15 at $20^{\circ} \mathrm{C}$ and 1.0 bar. Additionally, the areas where variability is observed do not seem to be much wider in Figure 16 than in Figure 15. However, the levels of RMS in these areas are overall higher. These observations seem to be somewhat in line with the those of Hung et al. [9] and Kashdan et al. [10], who found the variation in the spray envelope to be independent of the gas pressure for iso-octane pressure-swirl sprays, although the fuel temperature was not varied.

These effects of fuel temperature and gas pressure are quantified in graphs of plume penetration calculated for the left plume pair (plumes 1 and 6) against time for several conditions in Figures 17-20. For all fuels at the non-collapse conditions of $20{ }^{\circ} \mathrm{C}$ and at all chamber pressures, as shown in Figure 17 for 1.0 bar and in Figure 18 for 0.5 bar gas pressure, there is little variation in spray penetration between the fuels. It is observed that decreasing the gas pressure from 1.0 bar to $0.5 \mathrm{bar}$, increases the penetration by about $20-25 \%$. For $90{ }^{\circ} \mathrm{C}$ fuel temperature and 0.5 bar gas pressure, as shown in Figure 19, n-pentane (Fuel 6) exhibits noticeably lower penetration due to the extended spray collapse (see Figure 14), whilst the rest of the fuels still exhibit similar penetrations. The penetration of Fuel 2 ('heavy' gasoline) seems to be slightly higher than that of iso-octane's (Fuel 4 ) and that of standard gasoline's (Fuel 1). This may be attributed to the heavier components present in this fuel and to the shape of its distillation curve which lies to the right of the curves of all the other fuels in Figure 8. For the spray-collapse condition of $120^{\circ} \mathrm{C}$ fuel temperature and 0.5 bar gas pressure, there is measurable difference in plume penetration lengths between the tested fuels, as illustrated in Figure 20. For the fuels that are seen to collapse at this condition, which includes Fuels 3 and 5 (model and standard gasoline with additive respectively), as well as Fuels 1 and 6 (standard gasoline without additive and $n$-pentane respectively), as discussed previously for Figures 12 and 14 respectively, a similar penetration curve is observed. For the intermediate 'heavy' fuel (Fuel 2), the observed collapse is again less than that for the lighter fuels and this is manifested in a higher plume penetration rate (gradient of the curve) in Figure 20. Fuel 4 (iso-octane) which has the highest initial boiling point of all tested fuels shows the least spray collapse in Figure 9 and the highest penetration rate in Figure 20 . At $120^{\circ} \mathrm{C}$, the penetration of Fuel $6(n-$ pentane) was observed to be slightly higher than that of the model fuel due to the formation of a higher velocity jet down the centre of two combined plume jets.

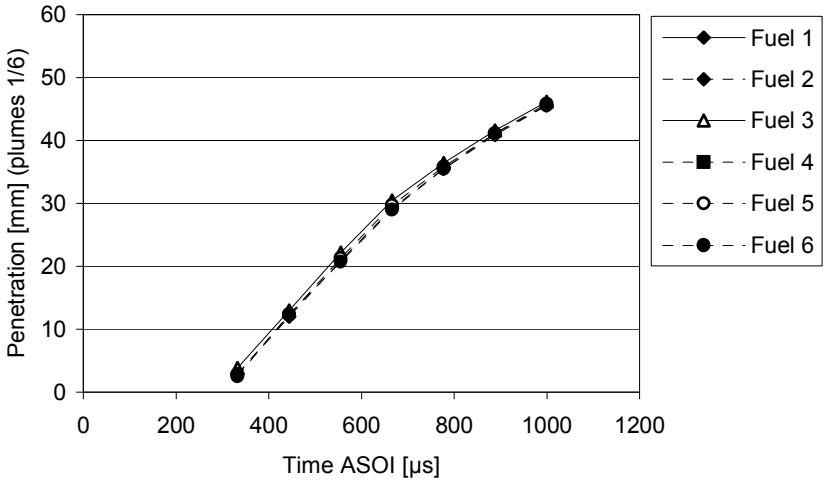

Figure 17. Spray Plume Penetration: $20{ }^{\circ} \mathrm{C}$ Fuel Temperature, 1.0 bar Gas Pressure.

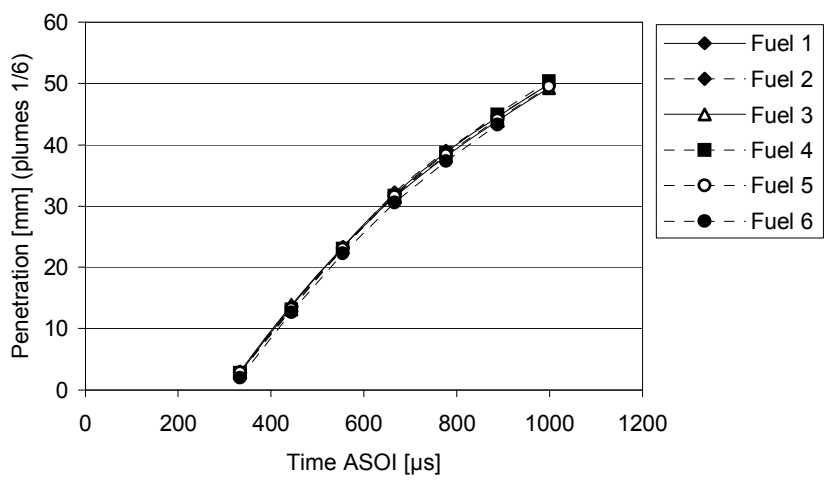

Figure 18. Spray Plume Penetration: $20{ }^{\circ} \mathrm{C}$ Fuel Temperature, 0.5 bar Gas Pressure.

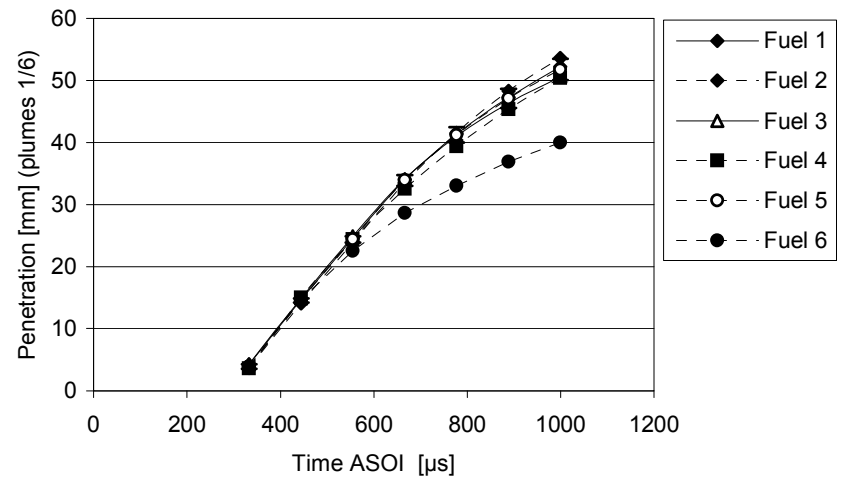

Figure 19. Spray Plume Penetration: $90{ }^{\circ} \mathrm{C}$ Fuel Temperature, 0.5 bar Gas Pressure.

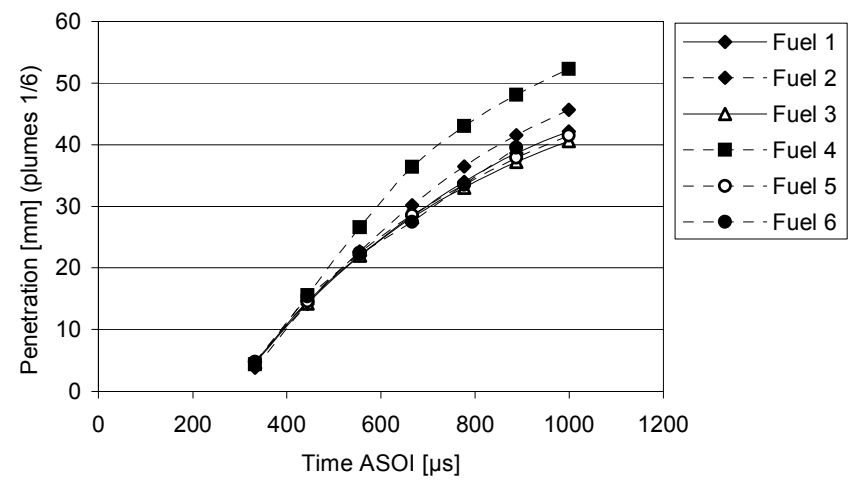

Figure 20. Spray Plume Penetration: $120^{\circ} \mathrm{C}$ Fuel Temperature, 0.5 bar Gas Pressure. 
' $\mathrm{t}$ '

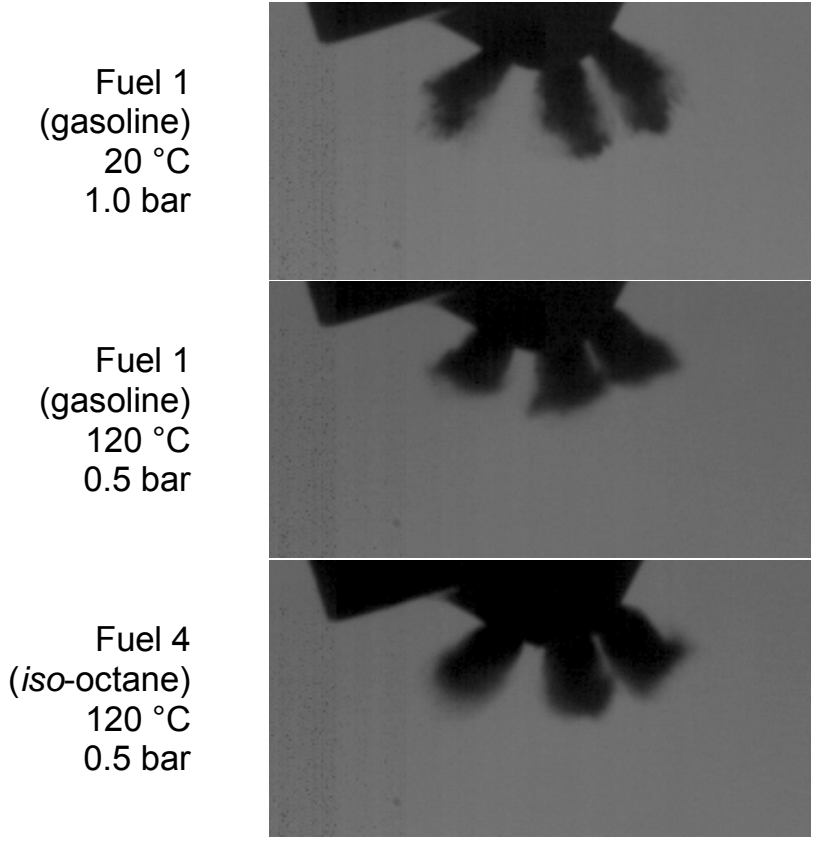

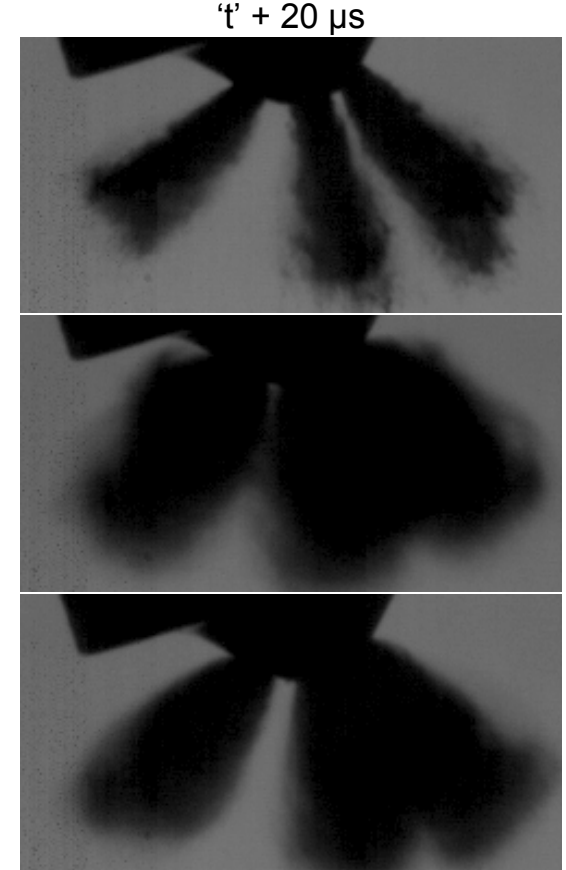

Figure 21. High-Speed High-Magnification Imaging of Early Spray Development, Side View.

High-speed, high-magnification imaging of the emergent spray was used to capture early spray formation. The images showing the 'first fuel' as seen at the nozzle of the injector at a frame rate of 50,000 frames/s are shown in Figure 21. For all sprays it is seen that the initial emergent fuel spray has relatively similar form for all cases, with one apparent jet emerging from each nozzle orifice. The second frame captures the spray $20 \mu \mathrm{s}$ after the 'first fuel' has been seen. Here the development of the global spray is commenced and the main features, such as a combined plume pair on the right hand side of the image, are clearly visible. A local expansion of the individual plume cone angles is also noticeable, especially for the spray collapse conditions (e.g. Fuel 1 , $120^{\circ} \mathrm{C}, 0.5 \mathrm{bar}$ ). The precise cause of this expansion, its physical derivation and effect on the global spray formation is subject of ongoing research by the authors. More details can be found in reference [11] and it is envisaged that future publications will provide further analysis of this aspect of early spray formation.

Whilst each individual plume may be seen to expand at the injector nozzle for spray-collapse conditions, the overall angle subtended by the extreme left and righthand plume pairs, as imaged from the side, is seen to decrease. This overall spray cone angle is of greater significance in relation to engine operation as it marks the outer boundary of the liquid spray and hence the rich air/fuel ratio area in the combustion chamber. The overall cone angles for the main tested fuels are shown in Figure 22. Fuel 4 (iso-octane) shows the least spray contraction for all tested conditions and thus has a slightly larger cone angle than the lighter component fuels. The small differences in cone angles between the fuels even at the 'ambient' condition of $20^{\circ} \mathrm{C}$ fuel temperature and 0.5 bar gas pressure, suggests that the fuel properties are affecting the spray formation and possibly the flow regime in the nozzles. However, this is speculative and is the subject of ongoing research by the authors. The contraction of the overall spray cone angle at $120^{\circ} \mathrm{C}, 0.5$ bar with respect to that at $20^{\circ} \mathrm{C}, 1.0$ bar is greatest for Fuel 6 ( $n$-pentane), by $\sim 30 \%$, being very similar to that at $90{ }^{\circ} \mathrm{C}$. The contraction is $16 \%$ for Fuel 1 (standard gasoline) and 8\% for Fuel 4 (iso-octane).

A contraction in overall cone angle is normally associated with a smaller footprint when viewed from the base. However, the observed contraction leads to an increase in 'wetted' footprint (i.e. more liquid in the footprint) when viewed from the chamber base (equivalent to the piston crown in an engine). It should be borne in mind that the injector is mounted at an angle of $19^{\circ}$ in the chamber and hence the view shown in the images is angled to that which would be seen from the piston crown in an engine, as presented in [12]. Figure 23 shows the total spray area as seen from the base view during spray development from 'first fuel' seen (333 $\mu \mathrm{s}$ ASOI) to a fully-developed spray form (1110 $\mu \mathrm{s}$ ASOI). For the reduced gas-pressure conditions (dashed lines), the initial rate of plume growth is greater than that for 1.0 bar gas pressures. At the 0.5 bar, $120{ }^{\circ} \mathrm{C}$ condition both fuels show wider plumes due the increased evaporation form the spray boundaries and so initial wetted area growth is more rapid for these conditions. The rate of growth reduces as the spray contracts and the radial rate of growth diminishes. The incomplete collapse of Fuel 4 (iso-octane) under these conditions, especially of the left-hand plume pair, results in a lower overall measured area, as can be visibly seen from the base-view images in Figure 16. In contrast, the radial growth of the 1.0 bar sprays produces a relatively steady growth rate throughout the spray development with a slight increase once a steady state has been reached. 


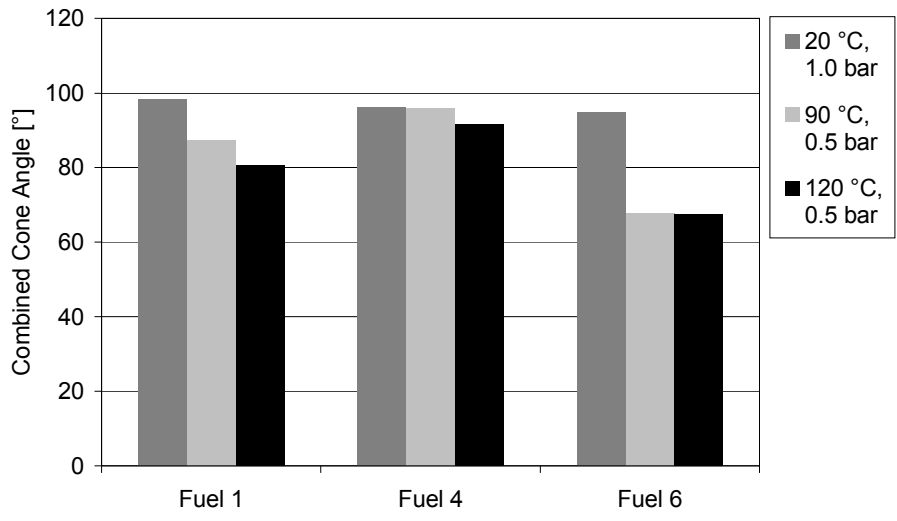

Figure 22. Spray Cone Angles for Outer Boundaries of Spray Envelope at $777 \mu \mathrm{s}$ ASOI.

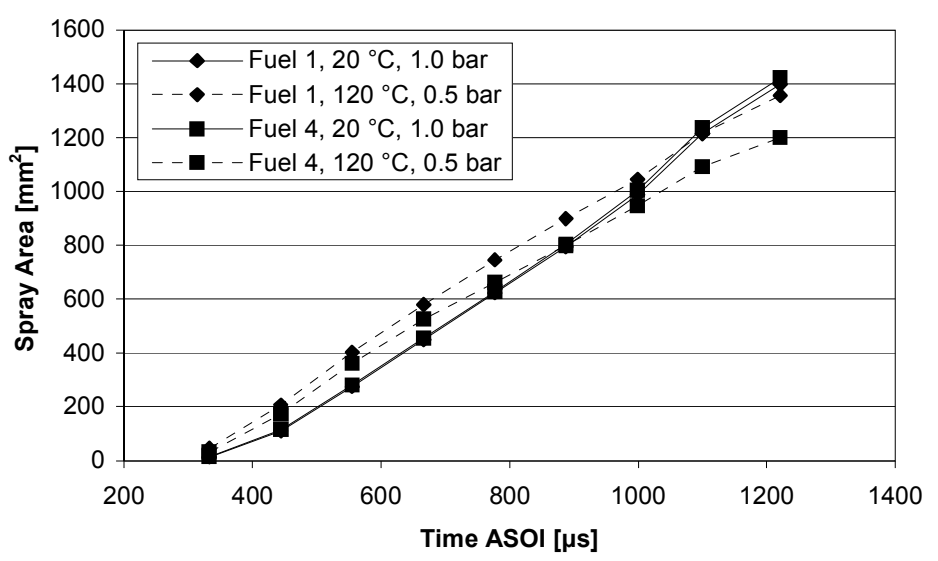

Figure 23. Base View Spray Areas.
Fuel 1

(standard gasoline)

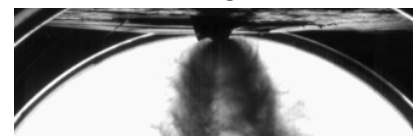

Mean Image
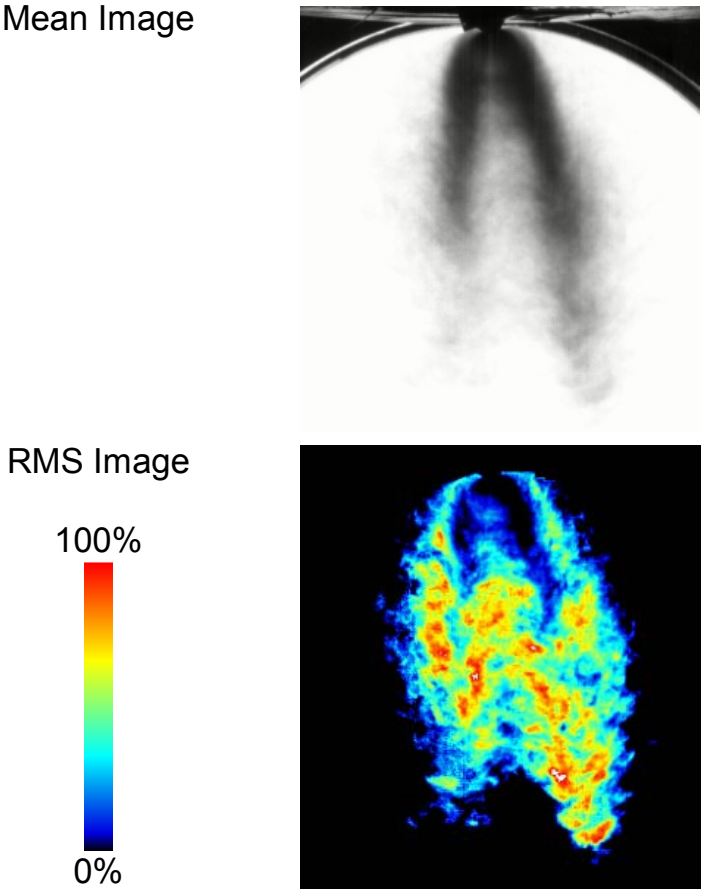

Fuel 4

(iso-octane)
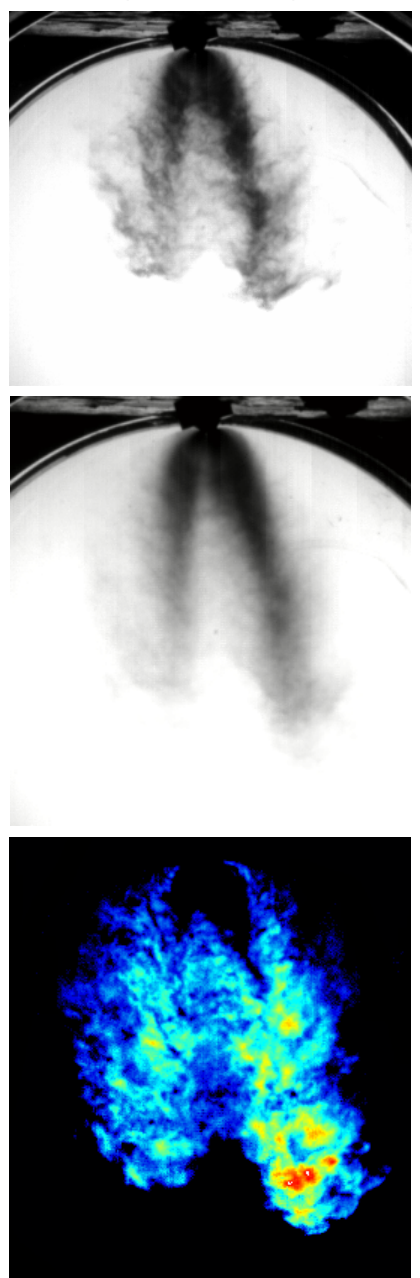

Fuel 6

(n-pentane)
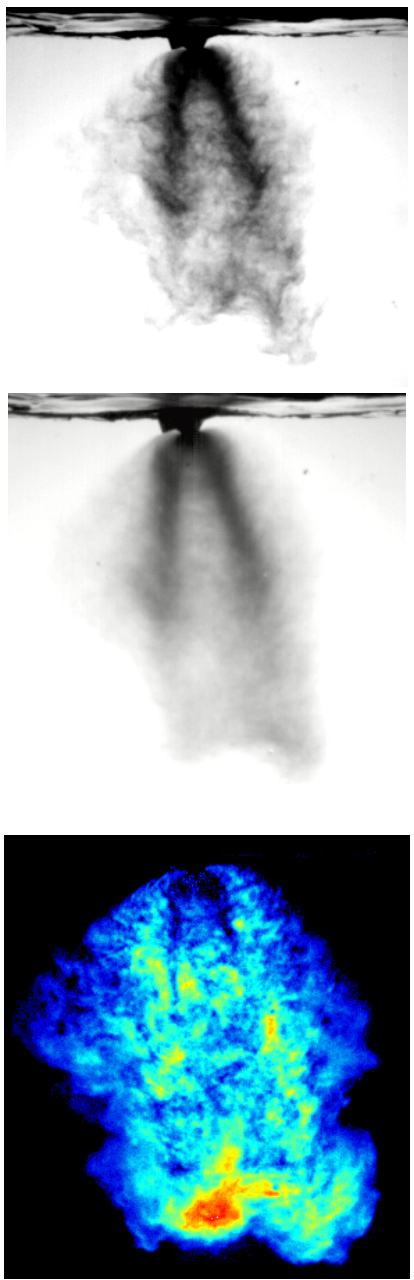

Figure 24. Spray Development: $180^{\circ} \mathrm{C}$ Fuel Temperature, 0.3 bar Gas Pressure, $777 \mu s$ ASOI, Side View. 
Increasing the fuel temperature to $180^{\circ} \mathrm{C}$ and reducing the gas pressure to 0.3 bar, produces the spray formations shown in Figure 24 for the different fuel types. Note that the lighting for Fuel 1 (standard gasoline) is somewhat brighter than that for the other fuels and hence some definition (mainly of small droplet formation) is unfortunately lost. In all cases a completely collapsed spray form is shown in as much as that the far right plume pairs have entirely combined to form a single jet. Further deviation from the 'normal' plume trajectory is evident in that the left hand plume pair and the right hand combined plumes appear to converge to a central axis, which due to the angular mounting of the injector is that of the chamber central axis. The spray for Fuel $6(n-$ pentane) shows the least liquid spray core (i.e. dense dark in the image) and the largest amount of fine droplets in the periphery (i.e. light grey cloud), suggesting rapid atomization around the core, as well as the shortest liquid core for the combined right-hand plume set due to vaporization of this core. Fuel 1 (standard gasoline) shows a core for the right-hand plumes with similar length to that of Fuel 4 (iso-octane), but a slightly longer dark liquid core with further penetration, despite the greater light intensity, for the left-hand plume pair, illustrating the presence of heavier, higher boiling components in this fuel than in Fuel 4 which have not yet vaporized at this time.

The small set of data acquired at each of the conditions of Figure 24 (10 injection events in comparison to 120 injection events taken for each condition and each fuel in all previous figures), as well as some inconsistency in the background lighting, precludes any definitive conclusions to be drawn but it is worth pointing out some features of the spray formation as observed in the mean and RMS images. In particular, although the dark liquid core appears to be fairly similar in shape for all fuels at this extreme condition of $180^{\circ} \mathrm{C}$ fuel temperature and 0.3 bar gas pressure, Fuel 6 ( $n$-pentane) exhibits a wider area of RMS. This area seems to be very similar in shape to that observed earlier for $n$-pentane in Figure 16 for $120{ }^{\circ} \mathrm{C}$ fuel temperature and 0.5 bar gas pressure. This suggests that for conditions beyond the point of major collapse, the spray tends to form and atomize without any further alteration in shape, but with an increased rate of evaporation. Fuel 4 (iso-octane) shows similar levels and areas of RMS, being slightly more compact in shape. Fuel 1 (standard gasoline) shows a narrower area of RMS in comparison to the other two fuels, as well as much larger areas of high RMS, but it is not currently clear whether this is related to the spray formation itself (because of the presence of both light and heavy components in this fuel), or has just been affected by the brighter, less consistent, lighting of this experimental test case.

Testing the single-component fuels cyclo-hexanone (with boiling temperature $155^{\circ} \mathrm{C}$ ) and acetone (with a much lower boiling temperature of $55^{\circ} \mathrm{C}$ and higher latent heat of vaporization), van der Wege and Hochgreb [1] found a similar spray contraction for a pressure-swirl injector at 0.3 bar gas pressure, $90{ }^{\circ} \mathrm{C}$ fuel temperature. In this case the acetone spray was observed to be considerably more compact, producing a near single, central jet, whilst the cyclo-hexanone produced a spray in which the conelike structure could still be identified, especially early on in the spray development (up to $1200 \mu$ s ASOI). The authors concluded that evaporated fuel vapor is drawn into the low pressure spray core, contracting the spray cone. Hence, the magnitude of contraction is directly related to the amount of fuel vapor present, which is a function of the excess of the prevailing fuel temperature and gas pressure conditions over the boiling temperature at the given gas pressure. A similar effect may be observed in Figure 16 where the greatest spray convergence is observed for the lowest boiling temperature fuel. These results mirror those of Davy et al. [7] who also observed the least spray collapse for a pressure-swirl atomizer with iso-octane relative to gasoline and a three-component model fuel at early injection and moderate temperature $\left(50^{\circ} \mathrm{C}\right)$.

As a general comment for all measurements presented in this paper, it needs to be pointed out that detailed data on surface tension, as well viscosity and associated temperature dependencies, have not been currently studied for all of the fuels and conditions tested and, although there is an effect of surface tension and viscosity on spray break up, as well as an effect of surface tension on vapor pressure for small droplets, no more certain conclusions on the origin of the differences observed between the different fuels should be drawn. However, droplet sizing, which is currently work in progress on this subject by the authors, along with detailed studies of all the physical properties of the fuels tested, will assist in further understanding the observed behavior for all fuels and conditions.

It may be said though, that, in general, a correlation between the observed fuel spray developments and the fuel bubble-point pressures can be identified. If the gas pressure is higher than the bubble-point pressure, all fuels behave very similar in terms of spray formation. If the gas pressure is lower than the bubble-point pressure at a specific fuel temperature for all fuels, the fuels with lower bubble-point pressure would be less evaporated and produce a less collapsed spray form. With reference to Table 2, for the conditions studied, it was observed that when the bubble-point pressure approached a value of the order 4-6 bar in that table, spray collapse was imminent for all fuels at the respective fuel temperature.

Particularly for single-component fuels, if the gas pressure is below the bubble-point pressure at the given fuel temperature, it would be suggested that the fuel would spontaneously vaporize, i.e. 'flash boil'. Whilst a much collapsed spray form was observed under such experimental settings, no spontaneous and complete vaporization of the fuel spray was documented, even under extreme gas pressure and fuel temperature conditions. This is probably because as 'flash boiling' starts to occur, the evaporation process takes heat away from the liquid and cools it down, which in turn inhibits 'flash boiling' of the fuel and brings about some form of 
equilibrium, or the fuel probably heats up again and the whole process repeats itself; i.e. there is a timescale relevant to the whole process. Therefore, it may be said that the level of superheat is important in two ways for the spray. Firstly it can influence the time taken for the spray to begin to flash, since it is a measure of the 'thermodynamic driving force' for moving the system towards equilibrium, and secondly it influences the amount of vapor that is produced during the flashing process. Thermodynamic calculations showed that for iso-octane at $120{ }^{\circ} \mathrm{C}$ at its bubble-point pressure, a constant enthalpy flash until it reached 1.0 bar, led to a vapor fraction of $0.198 \mathrm{~mol} / \mathrm{mol}$. By contrast, the same calculation for $n$-pentane led to a vapor fraction of 0.61 $\mathrm{mol} / \mathrm{mol}$. For flash calculations at the same initial conditions to 0.5 bar, the vapor fractions were 0.38 and 0.71 for iso-octane and $n$-pentane, respectively. These numbers have been quoted to demonstrate that the amount of superheat can affect the amount of vapor given off during the spray break-up process and they also illustrate that without heat transfer into the spray there is just not enough enthalpy in the system for the whole spray to evaporate. However, spray breakup behavior is not fully explainable by equilibrium thermodynamics on the basis that the enthalpy of the spray is constant. Rapid heat and mass transfer can alter this picture dramatically and a complete and thorough analysis of spray behavior on the basis of such equilibrium calculations is not possible.

For completeness, it should also be noted that the 'local' difference between the static pressure of the liquid fuel flow and the vapor pressure of the fuel has also been suggested to form the source of cavitation inside the injector nozzle, leading to changes in spray formation due to the increased rate of atomization and fuel vaporization upon ejection from the nozzle. There is some evidence to support the in-nozzle development of cavitation for the type of injector used in the current study and in particular how the formation of bubbles due to cavitation would provide nucleation sites for an increased rate of evaporation once released from the nozzle, for example by Gilles Birth et al. [13], as well as by our own studies [11], and further research on this forms part of our work in progress. However, it would appear that even at the most extreme cases of 'cavitation-induced' vaporization, combined with 'temperature-induced' vaporization, a timescale (that is perhaps also relevant to engine-cycle timescales) is one of the determining factors in the development of equilibrium during incylinder mixture formation.

\section{CONCLUSIONS}

This work has investigated the main factors affecting spray formation from a multi-hole injector for DISI engine applications. The experiments were carried out in quiescent pressure chambers. Six types of fuels with different grades of volatility were studied for a range of injector body temperatures, termed 'fuel temperatures' $\left(20^{\circ} \mathrm{C}\right.$ to $\left.180{ }^{\circ} \mathrm{C}\right)$ and chamber pressures, termed 'gas pressures' (0.3 bar to 1.0 bar), i.e. for conditions representative of in-cylinder phenomena for injection strategies during the intake stroke of an engine and for injector temperatures representative of typical enginehead temperatures. The tested fuels included various grades of multi-component gasoline (with or without additives), single-component fuels like iso-octane and $n$ pentane, as well as a multi-component model fuel blended specifically to mimic gasoline but also be suitable for in-cylinder LIF measurements. The fuel injection pressure was kept constant at 150 bar throughout all the experiments.

It was observed that the fuel properties have an important bearing on the spray development for multihole injectors operating at conditions close to the boiling point of the fuel for the prevailing gas pressure conditions. The greater the extent of temperature difference between the fuel and its boiling point (superheat), the greater the magnitude of spray collapse and the lower its plume penetration rate. However, within the practical limits of the experimental arrangement used in the current study, even at a fuel temperature that was about $70-160{ }^{\circ} \mathrm{C}$ higher than the boiling temperature of the fuel at the corresponding gas-pressure condition (1.0-0.3 bar, respectively), no spontaneous vaporization of the fuel was observed upon injection from the nozzle holes.

The main conclusions of this study on spray formation form a multi-hole injector for DISI engine applications can be summarized as follows:

- The development of sprays produced using isooctane and pump-grade gasoline fuels vary considerably at elevated fuel temperature and reduced gas pressure conditions which has implications on the use of iso-octane, as well as other single-component model fuels, for the diagnostics of injection systems and engines in general.

- Onset of spray collapse was not observed for isooctane at the condition at which all gasoline fuels and the lower boiling point single-component fuel ( $n$ pentane) were observed to exhibit collapse (typically at fuel temperatures of $90-120^{\circ} \mathrm{C}$ ). However, at a fuel temperature of $180{ }^{\circ} \mathrm{C}$, even iso-octane sprays exhibited full collapse.

- It was observed that for non-collapse conditions, decreasing the gas pressure from 1.0 bar to 0.5 bar, increased the penetration by about $20-25 \%$ for all fuels.

- The contraction of the overall spray cone angle at $120{ }^{\circ} \mathrm{C}$ fuel temperature and 0.5 bar gas pressure, with respect to that at $20^{\circ} \mathrm{C}$ and 1.0 bar, was greatest for $n$-pentane, by approximately $30 \%$, being very similar to that for $90{ }^{\circ} \mathrm{C}$ fuel temperature. The contraction in angle was $16 \%$ for standard gasoline and $8 \%$ for iso-octane. 
- The greater the difference between the gas pressure and the bubble-point pressure for a given fuel temperature, assuming that the bubble-point pressure is less than the gas pressure, the smaller the magnitude of spray deviation from its 'normal' form for all types of fuels tested.

- If the gas pressure is less than the bubble-point pressure, the magnitude of spray collapse increases. This is combined with the formation of a large amount of droplets, and hence presumably vapor, around the liquid spray core. However, spontaneous vaporization of the entire liquid fuel amount did not occur under any conditions tested (even at the combination of the lowest imposed gas pressure of 0.3 bar and the highest fuel temperature of $180^{\circ} \mathrm{C}$ ) and hence it appears that for all conditions a finite time is required for the vaporization to occur. The latter observation may be linked with the cooling process of the liquid fuel during evaporation that brings about some form of equilibrium as the degree of superheat influences the time taken for the spray to start to flash, but it also influences the amount of vapor that is produced during the flashing process.

- The difference between the prevailing fuel temperature and gas pressure conditions and the fuel's bubble-point pressure appears to be the driving force in spray development alteration. The bubble-point pressure can be used as an indicator of the susceptibility of a fuel spray to collapse under increased temperature and reduced pressure conditions. However, heat and mass transfer effects play an important role and a thorough analysis of spray behavior cannot be simply based on equilibrium thermodynamics.

\section{ACKNOWLEDGMENTS}

The authors would like to thank Shell Global Solutions (UK) Ltd. for fuel supplies and financial support, Dave Richardson, Steve Richardson, Stan Wallace, Xiangdong Chen and other staff at Jaguar Advanced Powertrain Engineering in the UK for injector supplies and continued technical and financial support, as well as the Engineering and Physical Sciences Research Council (EPSRC) in the UK for financial support under grant GR/S58850/01.

\section{REFERENCES}

1. van der Wege, B.A. and Hochgreb, S., "The Effect of Fuel Volatility and Operating Conditions on Fuel Sprays in DISI Engines: (1) Imaging Investigation", SAE Paper 2000-01-0535, 2000.

2. Areneo, L., Coghe, A., Brunello, G. and Donde, R., "Effects of Fuel Temperature and Ambient Pressure on a GDI Swirled Injector Spray", SAE Paper 200001-1901, 2000.

3. Stevens, R.E., Ma, H. and Stone, C.R., "On Planar Laser-Induced Fluorescence with Multi-Component
Fuel and Tracer Design for Quantitative Determination of Fuel Concentration in IC Engines", Proceedings of the Institution of Mechanical Engineers (IMechE), Part D, Journal of Automobile Engineering, Submitted, 2006.

4. Owen, K. and Coley, T., "Automotive Fuels Reference Book", $2^{\text {nd }}$ Edition, SAE, 1995.

5. Redlich, O. and Kwong, J.N.S., "Thermodynamics of Solutions: V. An Equation of State: Fugacities of Gaseous Solutions", Chemical Reviews, Vol. 44, pp. 233-244, 1949.

6. Silbey, R.J., Alberty, R.A and Bawendi, M.G., "Physical Chemistry", $4^{\text {th }}$ Edition, John Wiley and Sons, 2005.

7. Davy, M.H., Williams, P.A. and Anderson, R.W., "Effect of Fuel Composition on Mixture Formation in a Firing Direct Injection Spark Ignition (DISI) Engine: An Experimental Study using Mie-Scattering and Planar Laser-Induced Fluorescence (PLIF) Techniques", SAE Paper 2000-01-1904, 2000.

8. Moon, S., Choi, J., Abo-Serie, E. and Bae, C., "The Effects of Injector Temperature on Spray and Combustion Characteristics in a Single-Cylinder DISI Engine", SAE Paper 2005-01-0101, 2005.

9. Hung, D.L.S., Chmiel, D.M. and Markle, L.E., "Application of an Imaging-Based Diagnostic Technique to Quantify the Fuel Spray Variations in a Direct-Injection Spark-Ignition Engine", SAE Paper 2003-01-0062, 2003.

10. Kashdan, J.T., Shrimpton, J.S. and Acroumanis, C., "Dynamic Structure of Direct Injection Gasoline Engine Sprays: Air Flow and Density Effects", Atomization and Sprays, Vol. 12, pp. 539-557, 2002.

11. van Romunde, Z. and Aleiferis, P.G., "Effect of Operating Conditions and Fuel Volatility on Development and Variability of Sprays from Gasoline Direct-Injection Multi-Hole Injectors", Atomization and Sprays, in Press, 2007.

12. Serras-Pereira, J., Aleiferis, P.G., Richardson, D. and Wallace, S., "Mixture Formation and Combustion Variability in a Spray-Guided DISI Engine", SAE 2007 Powertrain and Fluid Systems Conference and Exhibition, October 29-31, Chicago, USA, SAE Paper 2007-01-4033, 2007.

13. Gilles-Birth, I., Rechs, M., Spicher, U. and Bernhardt, S., "Experimental Investigation of the In-Nozzle Flow of Valve Covered Orifice Nozzles for Gasoline Direct Injection", Proceedings of the $7^{\text {th }}$ International Symposium on Internal Combustion Diagnostics, pp. 59-78, May 18-19, Baden-Baden, Germany, AVL, 2006.

\section{ABBREVIATIONS}

ASOI After Start Of Injection (time interval after the start of the trigger pulse sent to injector driver)

ASTM American Society for Testing and Materials

DISI Direct Injection Spark Ignition

ETU Engine Timing Unit 
LIF Laser Induced Fluorescence

RMS Root Mean Square

RVP Reid Vapor Pressure

UNIFAC UNIversal quasichemical Functional group Activity Coefficient

\section{CONTACT}

Author for correspondence:

Dr. Pavlos Aleiferis

Department of Mechanical Engineering

University College London

Torrington Place

London WC1E 7JE

United Kingdom

E-mail: p_aleiferis@meng.ucl.ac.uk 